\title{
WestVirginiaUniversity
}

THE RESEARCH REPOSITORY @ WVU

Graduate Theses, Dissertations, and Problem Reports

2011

\section{Emotional Pain and Acute Nociception}

Alison M. Vargovich

West Virginia University

Follow this and additional works at: https://researchrepository.wvu.edu/etd

\section{Recommended Citation}

Vargovich, Alison M., "Emotional Pain and Acute Nociception" (2011). Graduate Theses, Dissertations, and Problem Reports. 4807.

https://researchrepository.wvu.edu/etd/4807

This Thesis is protected by copyright and/or related rights. It has been brought to you by the The Research Repository @ WVU with permission from the rights-holder(s). You are free to use this Thesis in any way that is permitted by the copyright and related rights legislation that applies to your use. For other uses you must obtain permission from the rights-holder(s) directly, unless additional rights are indicated by a Creative Commons license in the record and/ or on the work itself. This Thesis has been accepted for inclusion in WVU Graduate Theses, Dissertations, and Problem Reports collection by an authorized administrator of The Research Repository @ WVU. For more information, please contact researchrepository@mail.wvu.edu. 
Emotional Pain and Acute Nociception

Alison M. Vargovich

Thesis submitted to the Eberly College of Arts and Sciences

at West Virginia University

in partial fulfillment of the requirements

for the degree of

\author{
Master of Science \\ in \\ Psychology
}

Daniel W. McNeil, Ph.D., Chair

Kevin T. Larkin, Ph.D.

Aaron Metzger, Ph.D.

\author{
Department of Psychology \\ Morgantown, West Virginia \\ 2011
}

Keywords: Emotional Pain, Physical Pain, Tolerance Time, Chronic Pain 


\title{
Abstract \\ Emotional Pain and Acute Nociception
}

\begin{abstract}
Alison M. Vargovich
This study examined differences and similarities in responses to acute nociception in adults with a significant history of emotional pain relative to matched controls with a significant past positive life experience and a sample of chronic pain patients. Using 28 volunteers who responded to advertisements ( $n=14$, emotional pain group; $n=14$, positive life experience group), and 14 chronic pain patients from a prior study, this investigation utilized measures of pain threshold and tolerance during a laboratory finger pressure pain induction experiment. Each participant experienced two levels of pressure pain (i.e., high and low) and two levels of induced fear (i.e., high and low). Mixed between-within subject ANOVAs revealed a significant main effect of weight for pain threshold and tolerance, suggesting the importance of stimulus intensity. Exploratory analyses suggested an interaction between weight and group membership for pain tolerance. Findings indicate that individuals who are self-selected to talk about emotional pain possibly may have a higher pain tolerance for more intense pain stimulation as compared to participants reporting positive life events and chronic pain.
\end{abstract}




\section{Acknowledgements}

The completion of this thesis project came with a lot of support, guidance, and help from others. I would like to begin by thanking my committee members, Kevin Larkin and Aaron Metzger, for their helpful comments and suggestions. To my mentor, committee chair, and friend Dan McNeil, without your support and guidance I would not have been able to complete this project or learn so much about research and myself.

I want to thank all those in the Anxiety, Psychophysiology, and Pain Research Laboratory in the Department of psychology at West Virginia University who helped with my data collection, especially Cameron Randall and Grant Shulman. You both made the many hours of data collection much more fun and enjoyable.

Finally, I would not be the person I am without the influence of my family. To my parents, Paul and Suzanne, thank you for your constant love and support throughout my entire life. You have a funny way of encouraging me to persevere and have fun; work hard, play hard. Your dedication to our family is an inspiration and I miss you every day. To my Grandma Millie, the heart of our family, your kindness and love never fail to lift my spirits. To my siblings, Angela, Paul, Lisa, and Lauren, thanks for making me laugh and always reminding me that I still am the baby, no matter my age or degree. I love you all, and all of your little ones. Lastly, I would like to thank my friend and love, Mark, for his support and impeccable sense of humor. You help me to put things into perspective and never let me take myself too seriously. 


\section{Table of Contents}

Introduction

p. 1

Pain Related to Physical Nociception

p. 1

Acute Pain

p. 4

Chronic Pain

p. 5

Emotional Pain

p. 8

Statement of the Problem

p. 10

Research Questions

p. 13

Method

p. 13

Participants

p. 13

Apparatus and Materials

p. 15

Measures

p. 16

Instructions

p. 18

Procedure

p. 19

Results

p. 24

Experimental Design

p. 24

Recruitment

p. 25

Demographics and Background Characteristics

p. 25

Primary Data Analyses

p. 27

Exploratory Analyses

p. 29

Discussion

p. 30

Overall Findings

p. 32

Exploratory Analyses

p. 34 
Limitations

Future Research

Conclusion p. 35

p. 37

p. 38

p. 40

Appendices

p. 48

Tables

p. 68

Figures p. 77 


\section{Emotional Pain and Acute Nociception}

When an individual experiences an emotionally painful event, such as the death of a loved one or the end of a close relationship, the experience frequently is described as being physically painful even though there is no immediate proximal physical stimulus present to cause the pain. This response to an emotional event has been shown to be experienced very similarly to physical pain (Eisenberger, Jarcho, Lieberman, \& Naliboff, 2006; Eisenberger et al., 2003; Rainville, 2002). Chronic pain, physical pain that has been experienced for an extended period of time, has been found to result in greater sensitivity to laboratory-induced pain tasks (Hurtig, Raak, Kendall, Gerdle, \& Wahren, 2001; Kosek, \& Hansson, 1997). If emotional pain is experienced in a similar way to physical pain, it also could result in "chronic emotional pain” that possibly could result in emotional pain individuals experiencing greater sensitivity to laboratory-induced pain (Meeus \& Nijs, 2006; Melzack \& Wall, 1965). Alternatively, emotional pain could create habituation, and may result in lower sensitivity to laboratory-induced pain (Joiner, 2005). With differing theories yielding opposite predictions, it was hoped that the following study would be helpful in alleviating some confusion, providing a better understanding of emotional pain.

\section{Pain related to Physical Nociception}

Pain can be categorized based on type and severity, with biological and psychological effects intertwined in how it is experienced (Coffey \& Mahon, 1982). Pain is described as “an unpleasant sensory and emotional experience associated with actual or potential tissue damage, or described in terms of such damage” (International Association for the Study of Pain Task Force on Taxonomy, 1994, p. 211). While this definition provides a rudimentary description of 
pain, it does not describe the physiological processes that occur when an individual experiences pain.

Within the human body, there are sensory receptors, nociceptors that react specifically to aversive stimuli (Coffey \& Mahon, 1982; Willis \& Westlund, 1997). When the cells in the body are confronted with potentially damaging stimuli, the nociceptors send signals to the spinal cord and brain with the specific information on location of the aversive stimuli (Coffey \& Mahon, 1982; Willis \& Westlund, 1997). This pain message is a means for the cells in the damaged areas to communicate with the pain center in the brain via the spinal cord; allowing the body to signal any problems or malfunctions that may be occurring. There are different structures and locations of nociceptors, and while their specific task is to communicate pain information, it is not always necessary to have enacted these pain receptor pathways in order to experience pain (Price, 1999). It is important to note that the actual experience of pain involves more than nociception. It involves a reciprocal relation between psychological and physiological processes, which historically was unrecognized.

The early theories of pain focused solely on the physiology of pain as a response to aversive stimuli, although instead of pain receptors activating the pain center in the brain, Rene' Descartes proposed it was animal spirits responsible for the elicited behavioral response (Coffey \& Mahon, 1982). Advances were made from the time of animal spirits, specifically with the Gate Control Theory proposed by Melzack and Wall (1965). This theory was the first to integrate sensory, motivational, and cognitive components into the physiological response of pain (Melzack \& Wall). The concept that pain went beyond human physiology and involved psychological processes first was explored by Melzack and Casey (1968) through their three dimensions theory. The theory asserted that a person's appraisal of both unpleasantness and 
intensity of pain was influenced by the individual's cognitions about the pain. Specifically, they proposed that pain was experienced through three dimensions: sensory-discriminative, which classified the location, intensity, and duration of pain: affective-motivational, which described the unpleasantness felt and the desire to escape from it, and cognitive-evaluative, which entered cognitive appraisal of pain and cognitive coping techniques for pain into the total experiential framework (Melzack \& Casey). This theory aided in framing current conceptualizations of pain by including affect and cognitions jointly with physical sensation.

Further investigation demonstrated that the experience of pain is heavily influenced by psychological appraisal. The International Association for the Study of Pain (IASP) asserts, that while aversive stimuli do in fact activate the nociceptive response, that itself is "not pain.” The IASP goes on to state that pain is "always a psychological state, even though we may well appreciate that pain most often has a proximate physical cause” (1994). The perception of pain is an affective experience, due to its unpleasantness. It is based on an individual's biological predisposition and prior experience (IASP). The unpleasantness of pain contributes to the emotional reaction, which is used as a cue to either escape the situation and/or to avoid it in the future (MacDonald \& Leary, 2005). The painful sensation is the warning signal to the body and may produce a reflexive response. The pain affect, or emotional response, may vary depending on the stimulus and the individual. Over time, responses to pain sensation and pain affect may become habituated, through repeated exposure (LeBlanc \& Potvin, 1966; Strempel, 1976; Strempel 1978).

Through prior pain experiences, as well as biological predisposition and psychological effects, pain threshold and tolerance are established, although there certainly are environmental determinants as well. Pain threshold is designated as the point in which a stimulus first becomes 
painful to the individual. Pain tolerance is the greatest amount of pain an individual can endure before succumbing emotionally or physically (IASP, 1994). An individual's past pain experiences may influence future responses to aversive stimuli; however, there are ways in which pain threshold and tolerance can be altered by the environment or an individual's behavior. It has been found that an increased perception of control over the pain stimulus leads to higher pain tolerance in many individuals (Haythornthwaite, Menefee, Heinberg, \& Clark, 1998). Lower reported pain levels are associated with social support (e.g., active or passive) during the pain experience as compared to experiencing the pain alone (Brown, Sheffield, \& Robinson, 2003). These findings support the idea that the experience of pain can be effectively altered through psychosocial means, in addition to or instead of biological (e.g., pharmacological) mechanisms.

\section{Acute Pain}

The experience of acute pain often is described as sudden and sharp, and is a sign of possible injury, disease, or other aversive threat to the body (Grichnik \& Ferrante, 1991). There are varying degrees of acute pain from mild discomfort (e.g., a paper cut) to severe and long lasting (e.g., surgery and recovery). The majority of acute pain will go away on its own or can be addressed with a mild analgesic (Carr \& Goudas, 1999). If the pain is long lasting, it will be alleviated when the cause of the pain is treated or healed (Carr \& Goudas, 1999). The key factor separating acute pain from chronic pain is duration. Some definitions of chronic pain stipulate a shorter duration of pain ( $\geq 3$ months; Turk, Monarch, \& Williams, 2004) while others define it as lasting six months or longer (Grichnik \& Ferrante, 1991). Chronic pain may not have a direct proximal cause or it may be known, but possibly poorly understood (Grichnik \& Ferrante, 1991). 
A significant difference in responsivity to acute pain exists between chronic pain patients and healthy controls, when induced in the laboratory setting (Hurtig et al., 2001; Kosek, \& Hansson, 1997). Hurtig et al. (2001) utilized cold and heat acute pain tests on participants with fibromyalgia and healthy control subjects and discovered that pain thresholds differed between the two groups. The fibromyalgia group expressed greater sensitivity to the pain induction task than healthy controls as measured by lower pain threshold levels. The findings provide support for the central sensitization theory. In another laboratory-induced pain study, chronic pain patients responded with lower pain thresholds in response to a pressure pain task (Kosek \& Hansson, 1997). Research has demonstrated that there is a difference in responsivity to acute pain between individuals with chronic pain and healthy participants, but no research has been conducted to test acute pain in individuals suffering from emotional pain.

Acute pain, as previously mentioned, can be experienced in varying intensities. In a laboratory setting, the pain intensity can be controlled through changes in the physical stimuli used in the pain task. The intensity of pain can be altered through modifying weight, volume, temperature, and/or duration, depending on the specified task. Typically, by increasing the intensity of the stimuli, the condition is viewed by the participant as being more aversive (Vowles, McNeil, Sorrell, \& Lawrence, 2007). With the ability to manipulate pain intensity, it is possible to maintain a certain level of control needed to study the causes and effects of pain in a laboratory setting.

\section{Chronic Pain}

The major difference between acute and chronic pain is persistent activation of pain pathways beyond the normal healing period (Shipton \& Tait, 2005). One of the main diagnostic criteria for chronic pain is the duration beyond at least three months (Turk, Monarch, \& Williams, 
2004; Wolfe, Smythe, Yunus, et al., 1990); however, among patients there is a distinction between types of chronic pain. Some individuals suffering from chronic pain are able to cite an event which precipitated the pain. For example, with a back injury or chronic illness (e.g., diabetes), there is visible nerve damage to activate the symptoms, classified as neurogenic pain (IASP, 1994). Interestingly, however, some chronic pain patients do not have a trigger event, and experience ongoing pain without any known reason as to why, and without any visible damage in the inflicted areas, classified as psychogenic pain (Merskey \& Spear, 1967). Therefore, chronic pain can be difficult to medically pinpoint, and also is resistant to many typical medicinal pain treatments (IASP). As such, treatment requires a concerted effort between the medical and psychological health professions in order to effectively manage pain.

A leading theory regarding the antecedents of chronic pain is central sensitization, and ties in with the Gate Control Theory of pain (Melzack \& Wall, 1965). Non-pain transmitting neurons can interfere with the pain transmitting neurons and alter an individual's pain perception (Meeus \& Nijs, 2006). Running throughout the spinal cord, there is a pain regulating center, the dorsal horn, which receives pain signals from A-delta fibers that are associated with sharp pain and C fibers that are associated with dull pain (Meeus \& Nijs; Melzack \& Wall). When a third fiber, A-beta, which is associated with non-pain transmissions, interferes with the A-delta and C fibers, the non-pain fibers, in a sense, "close the gate” to the dorsal horn, which interferes with the pain message (Meeus \& Nijs; Melzack \& Wall). Both A-delta and C fibers also can interfere with the signal of the A-beta fibers and in turn "open the gate" to the dorsal horn (Meeus \& Nijs; Melzack \& Wall). Central sensitization occurs when the pain neurons affecting the dorsal horn areas become sensitized through repeated or continuous exposure to the signal from the pain fibers (Meeus \& Nijs). The outcome of this sensitization is an exaggerated response to pain 
stimuli and possibly a pain response to nonnociceptive stimuli (Baranauskas \& Nistri, 1998; Meeus \& Nijs; Staud \& Smitherman, 2002). The process of repeated exposure to pain stimuli through the dull pain C fiber to the dorsal horn is termed “wind-up,” and is closely related to chronic pain, as its outcome is a dull and nagging feeling of pain (Gracely, Grant, \& Giesecke, 2003; Meeus \& Nijs).

The two major psychological factors that have been repeatedly associated with chronic pain are anxiety and depression (Arnow, Blasey, Lee, Fireman, Hunkeler, et al., 2009; Bair, Wu, Damush, Sutherland, Kroenke, 2008; Haley, Turner, \& Romano, 1985; McCracken, Gross, Aikens, \& Carnrike, 1996). Because anxiety and depression often are comorbid, they may have a synergistic effect in chronic pain. Individuals suffering from anxiety or depression have an increased likelihood of experiencing chronic pain, and individuals who experience chronic pain are more likely to have symptoms of anxiety and depression (Bair et al.; Haley et al.; McCracken et al.). Therefore, a cycling of symptoms may occur, in which the effects of chronic pain create feelings of anxiety and/or depression and then the effects of anxiety and/or depression exacerbate the chronic pain symptoms (Bair et al.).

An individual's expectations of stimuli can influence one's experience of pain. The expectancy for pain can have an effect on perception and responsivity to stimuli (Al Absi \& Rokke, 1991; Bolles \& Fanselow, 1980; Williams, 1996). High pain expectancy may not cause an increased pain experience, but can increase fear and anxiety to which an individual may respond by avoiding the stimuli altogether (Buer \& Linton, 1999; Crombez, Vervaet, Baeyens, Lysens, \& Eelen, 1996). There are contradictory findings among the research. Some research has demonstrated that fear and anxiety increase the perception of pain (Al Absi \& Rokke), while others investigations have found that fear and anxiety decrease the perception of pain (Bolles \& 
Fanselow). One theory is that fear can act as a distraction from pain, resulting in a decrease in experienced pain and an increase in pain tolerance (Bolles \& Fanselow). Another theory emphasizes that fear can exacerbate nociception by altering an individual's perception of the pain (Al Absi \& Rokke). Other factors, perhaps individual differences, type of pain, or pain intensity, also may be involved.

\section{Emotional Pain}

While experiencing the death of a child or the betrayal by a close friend are not classified as physical pain, few would refute the fact that the pain experienced in these and other emotionally painful situations can be just as distressing as many physical injuries. Emotional pain, experienced as pain affect, can elicit a similar physiological response as pain related to a physical stimulus (MacDonald, 2009; Price, 1999). Individuals desire to escape from the pain just as in physical pain; however there is no obvious analgesic for relief.

The terminology used to describe emotional pain is extensive, including terms such as mental pain (Orbach, 2003), psychache (Shneidman, 1998), and social pain (Eisenberger, Leiberman \& Williams, 2003; Leary, Springer, Negel, Ansell, \& Evans, 1998; MacDonald \& Leary, 2005). Mental pain develops as a result of negative events an individual experiences, which leads to negative self-appraisal and in turn an overwhelming feeling of negative emotions (Orbach). Psychache, coined by Schneidman (1998), develops from unmet needs (e.g., feeling secure, loved, or in control), which manifest as emotional pain and can then lead an individual to turn to suicide as a way to terminally treat the pain. Social Pain, defined by hurt feelings and rejection, is theorized as a motivating factor in maintaining relationships and social connections (Leary et al.; MacDonald \& Leary). Maintaining relationships and connections with others is negatively reinforcing, as it removes the feelings of social pain. Finally, emotional pain has been 
defined by Bolger (1999) as a result of an individual recognizing a disconnect within themselves and with close relationships, which can lead to negative self-evaluation and aversive feelings. Each term is meant to describe pain that is related to psychosocial antecedents, and may not have a physical cause, but still is experienced intensely (Weinstein \& McNeil, 2011).

Because both pain sensation and affect are components of the nociceptive experience, pain caused by emotional distress may result in physical symptoms (e.g., headaches); however, physical injury is not required for emotional pain to be experienced (MacDonald, 2009). DeWall, MacDonald, Webster, Masten, and Baumeister (2010) used acetaminophen to preemptively treat emotional pain experienced as hurt feelings. After 15 days of treatment, the individuals taking acetaminophen reported lower levels of hurt feelings as compared to the placebo group. By linking emotional pain to physical pain symptoms and treatments, it becomes possible to explore the similarities between chronic pain and emotional pain constructs. Because chronic pain can be exacerbated by symptoms of depression and anxiety (Bair et al., 2008), perhaps emotional pain also could intensify symptoms of chronic pain. After experiencing emotional pain daily for an extended period of time, based on physical chronic pain criteria longer than six months (American Psychiatric Association, 2000), the emotional pain could be considered chronic. Certain psychological disorders can involve long term emotional distress (e.g., mood disorders, anxiety disorders); however, emotional pain appears to be experienced differently than these disorders. Perhaps emotional pain is a separate construct with some overlapping characteristics (e.g., feelings of sadness).

In addition to the physical symptoms that may be associated with emotional pain, it has a theoretical link with suicidality. Shneidman described this construct as psychache (Shneidman, 1998). He suggested that individuals become suicidal as a result of compounding negative 
emotions that are formed out of frustration from unmet emotional needs. Eventually, the constancy of the negative emotions becomes unbearable leading to suicide as a means of escape. Others have theorized that individuals who experience severe emotional pain may become hopeless and feel as though there are no other options to relieve the pain, resulting in suicide (Mee, Bunney, Reist, Potkin, Bunney, 2006). A suicide behavior theory proposed by Joiner (i.e., Interpersonal-Psychological Theory of Suicidal Behavior, 2005) suggests that suicidal individuals will experience gradual approximations of pain through self-exposure to different fear and pain situations, and often through self-injurious behaviors in order to accomplish suicide. More simply, individuals may consciously or unconsciously expose themselves to painful stimuli, which functions to increase their pain tolerance. Either consciously or unconsciously, one begins to isolate oneself, as to create a gap between themselves and society, all the while habituating to pain through the gradual approximations (Joiner, 2005). By increasing pain tolerance (i.e., habituation) the individual prepares one's self, both physically and psychologically, for the pain that is associated with committing suicide (Joiner). Joiner suggests that the means for habituation are exposure to physical pain stimuli; however, with the physiological overlap between physical pain and emotional pain, intense experiences of emotional pain itself increase pain tolerance as well.

\section{Statement of the Problem}

Previous research has established that certain chronic pain patients show greater sensitivity to laboratory-induced pain compared to healthy controls (Hurtig et al., 2001; Kosek \& Hansson, 1997), but there has been no research on acute nociception in individuals who have experienced significant emotional pain. Due to the connections between emotional pain and physical pain, examining pain responsivity in individuals experiencing emotional pain as 
compared to a chronic pain sample and a control group will allow for a greater understanding of pain, broadly conceived. A positive life event group was included as a contrast to the emotional pain participants and acted as a control group for both the emotional pain and chronic pain samples. The current study examines the similarities and differences between all three groups.

One way to assess the possibility of greater pain sensitivity or lower threshold and tolerance is to use an established algometer pressure pain device. Such a procedure was utilized by Sorrell (2000) with a sample of 40 chronic pain patients to examine the expectancies of and responsivity to fear and pain. Of this sample, 14 individuals were matched to the present study's 14 emotional pain and 14 positive life event controls, based on sex, age, and socioeconomic status. The aim of Sorrell's study was to determine the impact of fear on pain threshold and tolerance. The research on fear and pain is divided by differing conclusions, with some research suggesting that fear and anxiety may increase pain (Al Absi \& Rokke, 1991), while other studies found that fear and anxiety can decrease pain (Bolles \& Fanselow, 1980). Sorrell’s study investigated how the differing findings fared in a sample of chronic pain patients. The results demonstrated that within the chronic pain sample, significant effects were found in the pain intensity levels for pain threshold time and pain tolerance time, as well as a significant effect of gender found on pain tolerance time, with males exhibiting higher pain tolerance than females. In terms of fear and pain, a significant effect was found in heart rate in the high pain/high fear condition, in which heart rate was significantly increased, possibly suggesting synergism (Sorrell).

The current study implemented a similar procedure to Sorrell (2000) in order to assess how the emotional pain and positive life event group would respond to acute pressure pain as compared to the chronic pain sample. The primary goal was to determine support for one of two 
opposing theories: the theory of central sensitization and the Interpersonal-Psychological Theory of Suicidal Behavior.

Based on the theory of central sensitization (Meeus \& Nijs, 2006; Melzack \& Wall, 1965), individuals with a significant history of emotional pain may react similarly to chronic pain patients, in terms of responsivity to acute laboratory-based pain. Interpreting this theory in relation to emotional pain would suggest that the emotional pain group may experience repeated exposure to pain stimuli similarly to individuals suffering from chronic pain. If so, this repeated exposure to pain could create an exaggerated response to pain stimuli (Baranauskas \& Nistri, 1998; Meeus \& Nijs, 2006; Staud \& Smitherman, 2002).

Conversely, based on Joiner's Interpersonal-Psychological Theory of Suicidal Behavior (2005), the emotional pain group may have higher pain threshold and tolerance, relative to the chronic pain sample and the positive life event control group. Interpreting Joiner's theory in relation to emotional pain would suggest that exposure to situations causing emotional pain also may lead to habituation to pain stimuli. Because of the physiological overlap between physical and emotional pain (Eisenberger, Jarcho, Lieberman, \& Naliboff, 2006; Eisenberger et al., 2003; Rainville, 2002), the idea that emotional pain would provoke similar responses to physical pain in the context of habituation is plausible. A notable distinction between Joiner's theory and emotional pain is that pain habituation in Joiner's theory is exhibited by suicidal individuals. While the emotional pain group may exhibit signs of depression and anxiety, it does not necessarily mean that they are suicidal; however, by linking emotional pain to increased pain threshold and tolerance, it could provide evidence that may support or refute one aspect of Joiner's theory. 


\section{Research Questions}

The current study was exploratory in nature and so a priori hypotheses were not deemed appropriate. The primary aim was to examine how individuals with emotional pain responded to acute pain stimulation as compared to both chronic pain patients and a control group. The study attempted to determine support for one of two differing theories, as already noted. Based on central sensitization theory, which states that prolonged exposure to pain stimuli will increase pain sensitivity as seen in chronic pain patients (Meeus \& Nijs, 2006; Melzack \& Wall, 1965). It may be suggested that the emotional pain group is more sensitive to acute stimulation and has lower pain threshold and tolerance. Both the emotional pain and chronic pain groups then would be expected to have lower pain threshold and tolerance than the positive life event control group. Conversely, based on Joiner’s Interpersonal-Psychological Theory of Suicidal Behavior, which suggests that individuals expose themselves to increasing intensities of pain in order to habituate to the sensations (2005), the emotional pain group may be less sensitive to pain and with a higher pain threshold and tolerance. Based on this latter theory, the emotional pain group would be expected to have higher pain threshold and tolerance than the chronic pain and positive life event groups. In addition, the positive life event group would be expected to have a higher pain threshold and tolerance than the chronic pain sample.

\section{Method}

\section{Participants}

Using the research of Sorrell (2000) and the calculations outlined by Keppel and Wickens (2004), an effect size of $\omega^{2} \approx 0.25$ was estimated for the present study. An effect size of $\omega^{2} \approx$ 0.25 or greater is characterized as large (Keppel \& Wickens). The current study involved a total of 33 community dwelling participants with only 30 participants having usable data (e.g., 16 
reporting a significant experience with emotional pain and 14 healthy controls reporting a significant experience with positive life events). Of those 30, the emotional pain group and positive life event group were matched to include 14 participants in each group. Regardless of self-selected group, all participants were interviewed regarding positive life experiences and emotional pain experiences. In addition, 14 chronic pain patients from a previous study were selected as a comparison group (Sorrell). The two emotional pain participants not included in the primary analyses did not have matched controls in the positive life event group.

Within the emotional pain group, there were 9 females and 5 males. They ranged in age from 19 to 67 years $(M=50.50, S D=15.48)$. All participants identified themselves as Caucasian. The marital status of participants consisted of $35.7 \%(n=5)$ being single (and never married), 35.7\% $(n=5)$ being separated, divorced, or widowed, 21.4\% $(n=3)$ being married or living with their current partner, and 7.1\% $(n=1)$ had a partner outside of the home. Within the positive life event group, there were 9 females and 5 males. They ranged in age from 18 to 70 years $(M=$ 50.64, $S D=14.79)$. All participants identified themselves as Caucasian. The marital status of participants consisted of $50.0 \%(n=7)$ being married or living with their current partner, 38.6\% $(n=4)$ being divorced, and $21.4 \%(n=3)$ being single (and never married). Within the chronic pain group, there were 9 females and 5 males. They ranged from 26 to 56 years $(M=48.57, S D$ = 9.78). The sample participants were all Caucasian. The marital status of participants consisted of $71.4 \%(n=10)$ being married or living with their current partner, $14.3 \%(n=2)$ being single (never married), and 14.2\% ( $n=2)$ being divorce or separated. See Table 1 for demographic characteristics. Pre-established exclusion criteria were used to screen participants. Table 2 displays the exclusion criteria. Each participant was thanked for their participation, debriefed, provided with a list of mental health resources, and received $\$ 50.00$ following the completion of 
the tasks. (See Appendix A for a copy of the mental health resources; See Appendix B for the payment record form).

\section{Apparatus and Materials}

Algometer pressure device. In order to induce pain, participants were exposed to an algometer pressure device originally developed by Forgione and Barber (1971). It was later updated based on the research of Dougher, Goldstein, and Leight (1987), and then Rainwater and McNeil (1991) designed and diagrammed the model being utilized in the current investigation. Prior to participating, the order of weight conditions and fingers used was determined via Latin Square procedure for the purpose of couterbalancing (See Appendix C for Latin Square procedure). The emotional pain and positive life event participants were matched for order, however, the chronic pain sample lacked the necessary information to match for order. The participant places the pre-designated finger in between two pieces of wood and then a dull plastic wedge was placed on top of the finger positioning it on the second phalanx. At this point, weights of different mass were placed on top of the platform of the algometer in order to induce different intensities of pain. A total of five trials were utilized (e.g., an initial condition followed by four experimental conditions) as done in Sorrell. In this particular study, the middle and ring finger of each hand was utilized in the experimental conditions. The index finger of the participant's non-dominant hand was used in the first condition as an initial exposure to the algometer procedure and to reduce reaction effects. The maximum duration of exposure during the initial condition was capped at 2 minutes, and each experimental condition was capped at 5 minutes. The participant was able to terminate the stimulation at any time. Throughout each condition, pain threshold (e.g., when the stimulation first becomes painful) and pain tolerance (e.g., when the stimulation can no longer be endured) were timed via a hand-help stopwatch. 
Pressure weights. In this study, there were five different weights used to produce the pressure stimulation for each specific condition (i.e., 750g tan weight, 500g blue weight, 500g red weight, $1000 \mathrm{~g}$ blue weight, $1000 \mathrm{~g}$ red weight). For the initial exposure, a small tan cylindrical container weighing $750 \mathrm{~g}$ was used to introduce the algometer and how it feels to the participant. There were two large red cylindrical containers, one weighing $500 \mathrm{~g}$ and the other weighing $1000 \mathrm{~g}$, as well as two small blue cylindrical containers, one weighing $500 \mathrm{~g}$ and the other weighing $1000 \mathrm{~g}$. All four of these containers were used in the specified conditions of high pain/low fear, low pain/high fear, high pain/high fear, and low pain/low fear conditions in Sorrell (2000). The discrepancy between the appearance of the container and the actual mass of the container was designed as part of the fear manipulation, along with the differing verbal instructions. The pain stimulation did not last longer than five minutes and could be terminated at any time by the participant.

Threshold and tolerance signs. Figure 1 shows a representation of the "Painful" and “Stop Stimulation” signs used by participants to indicate when they reached their pain threshold (e.g., first feelings of pain) and pain tolerance (e.g., cannot endure any more pain). The threshold and tolerance signs were specifically designed by Sorrel to mimic a yield and stop sign. Both signs were placed closest to the non-stimulated hand during each condition, with the yield sign (e.g., threshold) placed closest to the algometer and the stop sign (e.g., tolerance) directly next to it.

\section{Self-Report Measures}

Beck Depression Inventory-II. The Beck Depression Inventory-II (BDI-II) is a 21 item self-report questionnaire which utilizes a four-point scale $(0=$ minimal to $3=$ severe $)$ requiring respondents to indicate the severity of depressive symptoms (Steer, Clark, \& Beck, 1999). The 
items on the BDI-II include questions relating to hopelessness, irritability, guilt, fatigue, weight loss, and lack of interest in sex. Both high internal consistency $(\alpha=.92)$ and high convergent validity have been established for the BDI-II based on Pearson Correlations between the BDI-II and the Depression scale of the SCL-90-R ( $r=.89)$ (Steer, Clark, \& Beck, 1999). The BDI-II is not displayed in an appendix due to its copyrighted status.

Anxiety Sensitivity Index. The Anxiety Sensitivity Index (ASI) is a 16 item self-report questionnaire meant to assess an individual's concern about the negative aspects of anxiety symptoms through a five-point Likert-style scale. This index was first developed by Steven Reiss in 1983 and was later published in 1985, followed by validation studies (Reiss, Peterson, Gursky, \& McNally, 1986). The ASI is utilized to determine an individual's concern over the negative effects of anxiety based on three lower order factors, (i.e., physical, psychological, and social concerns), which then load onto one construct of Global Anxiety Sensitivity (Stein, Jang, \& Livesley, 1999). It has been found that the ASI has good internal consistency $(\alpha=.88$ ) (Peterson \& Reiss, 1992). See Appendix D for a copy of the ASI.

Hollingshead's Measure of Socioeconomic Status. The Hollingshead measure of socioeconomic status (SES), known as the Hollingshead (1975), is a four factor measure of SES consisting of education, occupation, sex, and marital status. By combining the information from each of the four factors, an SES score was estimated through a system of values established for each criterion, which is then multiplied by an established factor weight (Hollingshead). After the factor's scores have been determined, they are totaled for a final SES score (Hollingshead). The totals can range from a high of 66 to a low of 8, maintaining that the higher the score, the higher the socioeconomic status. Research has shown high interrater reliability ( $r=.86$ to .91) and 
classification agreement ( $r=.81$ to .88 ) between the Hollingshead and other measures of SES (e.g., Nakao and Treas scale, Blishen, Carroll, and Moore scale) (Cirino et al., 2002).

Threshold. Pain threshold was determined by the participant and was explained as the moment the participant experiences any pain in their finger (IASP, 1994). In order to indicate when the participant reached their pain threshold, a simple sign, shaped as a triangle meant to represent a yield sign, was utilized for the participant to tap when the first pain sensations are experienced (See Figure 1). If the participant never touches the threshold sign, and therefore does not experience a pain level above zero, the threshold was considered as the duration of the algometer task (e.g., five minutes). Pain threshold times were recorded and entered in seconds.

Tolerance. Pain tolerance was determined by the participant and was explained as the maximum amount of time the participant can endure the pain stimulation (IASP, 1994), which they indicated by touching the tolerance sign. In order to assess when the participant reaches their pain tolerance, a simple sign shaped as an octagon meant to represent a stop sign, was utilized for the participant to tap when the pain can no longer be endured (See Figure 1). If the participant never touches the tolerance sign, then the tolerance was considered as the duration of the algometer task (e.g., five minutes). Pain tolerance times were recorded and entered in seconds.

\section{Instructions}

The same instructions utilized by Sorrell (2000) were used in the current study. Sorrell (2000) developed the instructions using word descriptors of pain from the McGill Pain Questionnaire (Melzack, 1975). The specific words utilized by Sorrell (2000, p. 12) in the instructions for the high and low fear conditions were selected as those that were "highest in agreement, as relating to areas of sensory, affective, and evaluative pain,” which was based on 
research that examined word choice used to describe pain intensity (e.g., Gaffney, Foenader, Reade, \& Burrows, 1987; Kremer \& Atkinson, 1984; Melzack \& Torgerson, 1971). The instructions also were utilized as a part of the fear manipulation, along with the appearance of the containers used with the algometer. The instructions also allowed for the researcher to express that the participant would be able to stop at any point he or she chooses. See Appendix E for high, low, and neutral (i.e., used in the initial exposure) verbal fear intensity instructions.

\section{Procedure}

The current investigation was one part of a larger study being conducted in tandem (Weinstein, 2009). The first part involved a dissertation intended to develop an emotional pain interview. The second part was the current study of acute nociception. Because of the overlap, it was determined that utilizing the same participants would be the best solution.

As such, a basic overview of how both studies were conjoined is needed to understand the entire flow of the current study's procedures. First, a brief telephone screening was conducted to determine eligibility for the study, as well as to collect demographic information, and schedule an appointment. Second, upon meeting at the appointment and after the consent process, demographic information was collected followed by the Emotional Pain Interview and the Positive Life Event Interview (Weinstein, 2009). After the two interviews, the self-report measures of psychological functioning were administered (e.g., ASI, BDI-II). Following the selfreport measures, the algometer task was conducted. Finally, each participant was debriefed explaining the purpose of both of the studies. Included in the debriefing was a list of local mental health services, the $\$ 50.00$ compensation, and if necessary, the participants were given information regarding reactions to emotional pain and grief as outlined by Shear (2003). Participation for both studies lasted between 120 to 180 minutes, depending on the length of the 
interviews. Participants were informed that they may discontinue the study at any time and may refuse to answer any question(s) without penalty. See Figure 2 for an illustration of the procedure and Figure 3 for the algometer procedure.

Participant recruitment. Participants were recruited from the community through various means including newspaper advertisements (e.g., Dominion Post), online advertising (e.g., WVU-Hospital intranet, eNews), and word of mouth. Different advertisements were used to recruit for the emotional pain and positive life event groups. Examples of these advertisements can be found in Appendix F \& G. Participants were instructed to call for more information or to schedule an appointment. Unexpectedly during the study, a newspaper article describing the project and how to participate was included in a local newspaper. If responding to the article, interested participants were asked whether they felt they had more or more intense emotional pain experiences or more or more intense positive life experiences. This question was asked to determine which group they would be placed in and to maintain self-selection. The emotional pain and the positive life event participants responding to the advertisements were self-selected to discuss significant emotional pain (e.g., suicide of a loved one) or positive life events (e.g., the birth of a child), respectively. Individuals were asked to select events that occurred at least one year prior to participation. Interested individuals were contacted, given more information about the study and then screened for eligibility. The amount of compensation for time spent was not disclosed until the end of the screening process to avoid coercion and ensure that individuals were not solely participating for the monetary incentive.

Phone screening. A brief telephone screening (i.e., 15-30 min) was conducted for the purpose of scheduling an appointment and to determine eligibility through the pre-established criteria (See Table 1). Participants were informed about the tasks involved in the study as well as 
potential risks and benefits prior to deciding to enroll. If eligible, participants were scheduled immediately and given directions. Participants were instructed to refrain from taking pain relievers, such as acetaminophen and ibuprofen, up to six hours prior to participation. If an individual was not eligible, they were thanked for their interest and informed that they were not eligible to participate. See Appendix H for a copy of the Telephone Screening Form.

Demographics and history. Following the consent process (See Appendix I for consent form), the recording devices (e.g., video camera and digital recorder) were turned on and the demographic information was collected. Only the review of demographic information and interview portions of the study were video and audio recorded. The algometer portion was not recorded. Included were: education level, race or ethnicity, age, current relationship status, current job status, current occupation, annual household income, mental health treatment history, current medication use, and history of medical conditions. See Appendix J for a copy of the Demographic Information Form.

Administration of self-report measures. After collecting the demographic information, the emotional pain and positive life event interviews were administered. After completion, the participants were asked to complete several measures of psychological functioning including the ASI and the BDI-II. Both of the measures were utilized to determine participants’ anxiety sensitivity and depressive symptoms, respectively, as well as to determine any group differences in these symptoms. Anxiety and depression have been found to correlate with emotional pain (Orbach, 2003; Price, 1999) as well as chronic pain (Bair et al., 2008). The ASI and the BDI-II were used to assess the participants' experience of both anxiety and depression with a possible link to emotional pain. 
Algometer task. The algometer task followed the interviews and self-report measures. The individual conducting the interview sat at the end of the table and a laboratory member of the opposite sex of the interviewer administered the algometer task. The purpose of having a male and female in the room was to counterbalance the sex and control for gender expectancies. The algometer task began with the participant being introduced to the individual administering this portion of the study. Prior to the first exposure, the hand, finger, and weight being used in each of the four experimental conditions was determined through a Latin Square procedure (Keppel, 1991; Myrtek \& Spital, 1986). The participant sat at the table directly across from the researcher. The algometer and threshold and tolerance signs were all in their designated positions (Sorrell, 2000). The weights were kept hidden from the participant in a briefcase next to the researcher. See Figure 4 for a picture of the experimental setting.

The researcher then described the algometer task while demonstrating the procedure on themselves. Appendix K shows the general description used in this process. Following this description, the participant was asked if they had any questions prior to beginning the initial exposure.

Initial exposure. The participant then was asked which was their dominant hand and instructed to place the index finger on their non-dominant hand into the algometer. The researcher then tightened the screws located on the algometer to hold the participants finger in place, not to inflict any pain. Next, the researcher placed the tan $750 \mathrm{~g}$ weight onto the table and read the neutral instructions (See Appendix E for neutral instructions). After the instructions were read, the $750 \mathrm{~g}$ weight was placed on top of the algometer, while simultaneously starting the timer. Prior to placing the weight, participants were reminded to touch the threshold sign when the pressure changed from uncomfortable to painful, and touch the tolerance sign when they can 
no longer handle the discomfort. When the tolerance sign was touched, the weight was immediately removed. If the participants did not touch the tolerance sign, the condition was automatically terminated at two minutes. After the initial exposure, the $750 \mathrm{~g}$ weight was removed from the table and the participant's finger was released from the algometer.

Experimental conditions. At this point, any questions the participant had were answered prior to starting the first experimental condition. The experimental conditions began similarly to the initial exposure. The participant's pre-determined finger was placed in the algometer, the predetermined weight for the condition was placed on the table, and then the pre-determined instructions were read for the condition. Following the instructions, the participant was reminded to touch the yield sign when the stimulation first becomes painful and the stop sign when they could no longer handle the stimulation. The weight then was placed on the algometer platform, while simultaneously starting the timer. When the tolerance sign was touched, the weight was immediately removed. If the participants did not touch the tolerance sign, the condition was automatically terminated at five minutes. After the exposure, the weight was removed from the table and the participant's finger was released from the algometer.

The same procedure was used for the remainder each of the four experimental conditions. Each started by placing the participant's finger in the algometer, placing the weight for the condition on the table, reading the specific instructions for the condition, and then recording the times for both threshold and tolerance as determined by the participant. The four experimental conditions were counterbalanced across participants. When the final condition was complete, the participant was debriefed and any questions answered. See Figure 4 for an image of the algometer and room set-up. 
Debriefing. Following the algometer task, all participants were thoroughly debriefed on both studies. Participants were provided with a list of psychological services, as well as psychoeducational information about emotional pain and grief that are commonly experienced by individuals (Shear, Frank, Houck, \& Reynolds, 2005). The grief treatment protocol was in place to respond to any participants as needed; however, this protocol did not have to be utilized in the current study. If an individual expressed interest in treatment, they were referred appropriately. Following completion, participants were thanked for their time and interest in the study and were given $\$ 50.00$ compensation.

\section{Results}

\section{Experimental Design}

A 3 X 2 X 2 mixed between-within design was employed, comprised of three between subject groups (e.g., emotional pain, positive life event, and chronic pain groups), two within subject levels of fear instructions (e.g., high and low), and two within subject masses of weight in a pressure pain task (e.g., high and low), based on the study by Sorrell (2000). Sorrell (2000) examined the expectancies and responsivity to fear and pain with a sample of 40 chronic pain patients. The aim of Sorrell's study was to determine the impact of fear on pain threshold and tolerance. To match the procedures utilized by Sorrell, a fear manipulation also was included in the current study; however, the aim of the current investigation was to determine how different groups responded to acute pain stimulation, with fear being a variable of consideration. In addition, a Latin Square procedure similar to that in Sorrell's study was utilized to determine condition, hand, and finger order for participants.

\section{Recruitment}


There were 175 phone calls from 112 different individuals were received over the course of the recruitment from December 1, 2010 to May 25, 2011. All 175 phone calls were answered and/or voicemail messages were returned. Of the 112 individuals, 30 were rejected because there was no match across the groups. Of the remaining 82 individuals, 56 participants were screened for eligibility and 47 were found to be eligible to participate. The 26 who were not screened did not return follow-up calls. Of the 9 individuals not eligible for the study, the reasons were being currently pregnant (1), experiencing psychotic symptoms (2), suffering from fibromyalgia (1), unable to be matched (3), experiencing significant chronic pain (1), or a nerve condition affecting sensation in the hands (1). One participant stated she did not have a positive life event significant enough to discuss. Forty-three of the 47 participants scheduled appointments to participate in the study. Of the 43 participants, 33 came in for their appointment. Due to experimenter algometer implementation errors, only data from 30 of the 32 participants were usable. A total of 28 participants were included in the analyses $(n=14$ emotional pain participants; $n=14$ positive life event participants). The 28 participants were recruited from newspaper advertisements (9), Ruby Memorial Hospital website (9), a newspaper article about the study (4), advertising in psychology classes (3), eNews (1), and word of mouth (2). All participants were self-selected as either emotional pain or positive life event participants. See Figure 6 for a consort flow diagram.

\section{Demographics and Background Characteristics}

The mean age of the sample was 49.9 years $(S D=13.3)$, and participants across groups did not differ significantly in age, $F(2,39)=.10, p=.90$. There were 27 females $(64.3 \%)$ and 15 males (35.7\%), and the number of males and females was equivalent across groups. There were no ethnicity differences among the groups as all participants were Caucasian $(N=42,100 \%)$. 
Across the sample, the average socioeconomic status (SES) based on the Hollingshead measure of SES was $46.0(S D=10.1)$ out of a possible range of 8 to 66 . Participants did not differ across groups in terms of SES, $F(2,39)=2.59, p=.09$.

Further analyses were conducted to investigate possible group differences in terms of acute and chronic pain experiences currently and in the past, current use of medications, and current and past counseling. Analyses between the emotional pain group and the positive life event group showed that there were no significant group differences in participants’ report of currently experiencing chronic pain (yes $=8$ of 28), $\chi^{2}(1, \mathrm{n}=27)=.12, p=.73$, experiencing chronic pain in the past (yes $=10$ of 28$), \chi^{2}(1, \mathrm{n}=27)=1.36, p=.24$, currently experiencing acute pain (yes $=2$ of 28$), \chi^{2}(1, \mathrm{n}=27)=1.75, p=.19$, or experiencing acute pain in the past (yes $=25$ of 28), $\chi^{2}(1, \mathrm{n}=27)=.18, p=.67$. There was no significant difference between the emotional pain and positive life event group’s current use of medications (yes = 22 of 28), $\chi^{2}$ (1, $\mathrm{n}=27)=.57, p=.45$, as measured by if they were or were not currently on medication. There was no significant group differences in the participants' report of current counseling (yes = 3 of 28), $\chi^{2}(1, \mathrm{n}=27)=.00, p=1.00$, or previous counseling, (yes $=15$ of 28$), \chi^{2}(1, \mathrm{n}=27)=.00, p$ $=1.00$. The chronic pain sample was not included in these additional analyses as the necessary information was not available.

In addition, possible differences between the emotional pain group and positive life event groups were examined. During the interview, participants were asked to identify any additional positive life events or emotional pain events in their life. Analyses revealed no significant differences between the groups for either emotional pain, $t(25)=2.02, p=.054$, or positive life events, $t(25)=-1.72, p=.10$. See Table 3 for means and standard deviations. Participants also were asked to rate the intensity of the event, 0 not at all intense, to 100 the most intense 
emotional experience ever, and there were no significant differences between the groups for either emotional pain, $t(25)=-1.32, p=.20$, or positive life events, $t(25)=-.11, p=.92$. See Table 3 for means and standard deviations.

\section{Primary Data Analyses}

\section{Self-report of anxiety and depression}

A one-way analysis of variance (ANOVA) was conducted to assess possible differences in anxiety sensitivity (i.e., ASI score) among groups. There was a significant difference among the three groups, $F(2,39)=4.94, p<.05$. The actual difference in mean scores between the groups was large based on Cohen’s guidelines (1988). The effect size, calculated using eta squared, was .20. Post-hoc comparisons using the Tukey Honestly Significant Difference (HSD) test indicated that the mean score for the chronic pain group $(M=29.2, S D=13.1)$ was significantly higher than emotional pain group $(M=18.3, S D=10.1)$ and the positive life event group $(M=18.5, S D=7.6)$, which did not differ from one another. See Table 4 for ASI and BDI-II information.

The impact of group membership on depression, as measured by the Beck Depression Inventory (BDI-II) also was explored using an ANOVA. There was a statistically significant difference at the $p<.05$ level in BDI-II scores among the three groups, $F(2,39)=34.03, p$ $<.001$. The effect size, calculated using eta squared, was .64, which is considered a large effect size (Cohen, 1988). Similarly to the ASI, post-hoc comparisons using the Tukey HSD test indicated that the mean score for the chronic pain group $(M=26.4, S D=10.1)$ was significantly different from the emotional pain group $(M=9.9, S D=5.6)$ and the positive life event group $(M$ $=4.8, S D=5.0$ ), which did not differ from one another. See Table 4 for ASI and BDI-II information. 


\section{Comparison of conditions across time}

Pain threshold. A mixed between-within subjects ANOVA was conducted to assess the impact of three different variables (i.e., weight, fear instructions, group membership) on participants' pain threshold time across four conditions (low fear/low weight, low fear/high weight, high fear/low weight, high fear/high weight). There was no significant interaction between instructions and group membership, $F(2,39)=1.41, p=.26$, or instructions and weight, $F(2,39)=.03, p=.87$. The interaction between weight and group membership approached significance, $F(2,39)=3.18, p=.05$, with the emotional pain group having higher pain threshold times during the high weight conditions as compared to the positive life event group and chronic pain group. There was a significant main effect for weight, $F(2,39)=35.46, p$ $<.001$, partial eta squared $=.48$, which is consistent with the significant interaction showing change in pain threshold depending on the weight being used. The main effect for the three groups approached significance, $F(2,39)=3.13, p=.06$, partial eta squared $=.14$. See Table 5 for mean pain threshold times and Table 7 for the ANOVA information.

Pain tolerance. Similarly to threshold, the same analyses were conducted to assess the impact of weight and fear instructions on participants' tolerance time across the four conditions (low fear/low weight, low fear/high weight, high fear/low weight, high fear/high weight). There was no significant interaction between instructions and group membership, $F(2,39)=.69, p$ $=.51$, or fear instructions and weight, $F(2,39)=1.82, p=.19$. The interaction between weight and group membership approached significance, $F(2,39)=2.73, p=.08$, partial eta squared $=$.12. See Table 6 for mean pain tolerance times. A significant main effect was found for weight, $F(2,39)=47.74, p<.001$, partial eta $=.53$, which is specific to the high weight conditions. The main effect comparing the three groups was not significant, $F(2,39)=.66, p=.52$, partial eta 
squared $=.03$, suggesting no difference in membership between the three groups. See Table 8 for ANOVA information.

In addition, information about the number of participants to reach the maximum tolerance of 300 seconds was examined. Of the 56 different trials in each group, 30 of the emotional pain participants reached the maximum tolerance without escaping. In the positive life event group, 17 of 56 reached the maximum, and 22 of 56 reached 300 seconds in the chronic pain sample. See Table 9 for a complete portrayal across conditions.

\section{Assessment of possible covariates}

Pain threshold. In subsequent analyses, the ASI and BDI-II were added as covariates both independently and then conjointly to the pain threshold analyses. The inclusion of the ASI independently did not change the results of the analyses. A significant main effect for group membership was found after including the BDI-II independently, $F(2,38)=4.37, p<.05$, partial eta squared $=.19$, as well as including the ASI and BDI-II together as covariates, $F(2,38)$ $=6.64, p<.05$, partial eta squared $=.26$, with the emotional pain group having higher pain threshold as compared to both the positive life event and chronic pain groups.

Pain tolerance. Similarly, the ASI and BDI-II were added as covariates independently and conjointly to the pain tolerance analyses. Including the ASI as a covariate did not change the results; however the interaction between weight and group membership moved closer to significance, $F(2,38)=3.07, p=.06$, partial eta squared $=.14$. The inclusion of the BDI-II independently and jointly with the ASI did not change the results of the analyses.

\section{Exploratory analyses}

There were two additional emotional pain participants that did not have matched controls in the positive life event group, as such they were excluded from the primary analyses; however, 
inclusion of these two participants yielded interesting results. The revised emotional pain group ranged in age from 19 to 67 years $(M=49.8, S D=14.7)$ and the average SES based on the Hollingshead measure of SES was $51.19(S D=9.98)$ out of a possible range of 8 to 66 . The following results are based on 16 emotional pain participants, 14 positive life event participants, and 14 chronic pain patients.

Pain threshold. Inclusion of the two additional emotional pain participants did not change the results of the impact of instructions and weight on pain threshold. The results were consistent with the findings described in the primary analyses.

Pain tolerance. A mixed between-within ANOVA was conducted to determine the impact of weight and instructions on pain tolerance. A significant interaction between weight and group membership was found, $F(2,41)=3.59, p<.05$, partial eta squared $=.15$, with the emotional pain group having higher tolerance times during the high weight conditions as compared to the positive life event group and chronic pain group. See Figure 5 for the interaction. The main effect of weight remained significant. The main effect for instructions approached significance, $F(2,41)=3.43, p=.07$, partial eta squared $=.01$ as well as the interaction between instructions, weight, and group membership, $F(2,41)=2.48, p=.09$, partial eta squared $=.11$.

Assessment of possible covariates. The ASI and BDI-II were added as covariates both independently and conjointly to the pain threshold and tolerance analyses. Including the ASI and BDI-II separately and together did not change the results of the analyses.

\section{Discussion}

The main goals of this study were to: (a) explore the differences between emotional pain, positive life event, and chronic pain samples, (b) examine the effects of emotional pain on acute pain threshold and tolerance, and (c) determine if emotional pain participants’ responsivity to 
acute pain supports the theory of central sensitization (e.g., lower tolerance, more sensitive to pain) or Joiner’s Interpersonal-Psychological Theory of Suicidal Behavior (e.g., higher tolerance, habituated to pain). To achieve these goals, 29 community dwelling participants were exposed to a pressure-pain task with two masses of weight and two types of instructions (i.e., high and low fear). Using a mixed between-within subjects design, each participant experienced four experimental conditions. Participants were assessed using the ASI and BDI-II. There were six main findings:

1. There was a significant difference in scores on the ASI and BDI-II between the chronic pain group and the emotional pain and positive life event group. The chronic pain participants had significantly higher scores on both the ASI and BDI-II as compared both the emotional pain and positive life event groups. This difference is expected considering that chronic pain is highly comorbid with symptoms of depression and anxiety (Arnow et al., 2009; Bair et al., 2008; Haley, Turner, \& Romano, 1985; McCracken et al., 1996).

2. The interaction between weight and group membership for pain threshold approached significance. The emotional pain group appears to differ in the higher weight conditions as compared to the positive life event group and chronic pain group. When the pain stimulus was less intense, the three groups do not appear to differ.

3. There was a significant main effect of weight for pain threshold. The emotional pain, positive life event, and chronic pain groups had higher threshold times for the low weight conditions and lower threshold times for the high weight conditions. This finding is consistent with the literature in that the intensity (e.g., higher weight) of the stimulus is influential on pain perception (Vowles et al., 2007). 
4. The interaction between weight and group membership for pain tolerance approached significance. The emotional pain group appears to differ in the high weight conditions as compared to the positive life event group and chronic pain group. When the pain stimulus was less intense, these three groups do not appear to differ significantly. The change in pain intensity associated with the high weight conditions demonstrated that the emotional pain group had higher pain tolerance than the positive life event group and chronic pain group, though not significantly. Based on this finding, it appears that individuals who have experienced intense emotional pain may become habituated to acute pain stimulation, providing support for Joiner's theory of suicide.

5. There was a significant main effect of weight for pain tolerance. Because of the nearly significant interaction between weight and group membership, this finding reinforces the significance of the high weight conditions over the low weight conditions.

6. The analyses of covariates revealed a significant main effect of group membership for pain threshold when the BDI was included independently and conjointly with the ASI. This finding demonstrated that there may be a difference between the three groups after covarying for depression and anxiety symptoms.

\section{Overall Findings}

The first main goal of the current investigation was to explore the differences between the emotional pain, positive life event, and chronic pain groups. The emotional pain, positive life event, and chronic pain groups were equivalent based on age, sex, race, and SES. There were no significant differences between the emotional pain and positive life event groups for current and past chronic and acute pain. The lack of differences between these three groups is alone an interesting finding. The participants in each group appear to be quite similar to one another 
except in one respect. The groups differed based on their self-reported depression and anxiety symptoms as measured by the BDI-II and ASI, respectively. It is no surprise that the participants in the chronic pain group endorsed more depression and anxiety symptoms as they often are correlated with chronic pain (Arnow et al., 2009; Bair et al., 2008; Haley, Turner, \& Romano, 1985; McCracken et al., 1996).

The second goal of this study was to examine the effects of emotional pain experiences on acute pain threshold and tolerance. The pain threshold findings were muddled by difficulties inherent to assessing threshold (e.g, participant confusion, vague descriptions). Because of this issue, the pain threshold findings should be interpreted with caution. The analyses on pain tolerance appears promising; however because the interaction was not significant there is no conclusive evidence. Based on the interaction between weight and group membership and the significant main effect of weight for pain tolerance, there may be a difference in the pain tolerance similar to that found in pain threshold. The exploratory analyses suggested that the emotional pain group may have higher pain tolerance compared to the positive life event group and the chronic pain group. From the results, one could infer that the emotional pain participants are able to endure more intense pain stimulation for longer periods of time; however that was not conclusively substantiated by the analyses.

The final aim was to determine if emotional pain participants’ responsivity to acute nociception would support the theory of central sensitization (e.g., lower tolerance, more sensitive to pain) or Joiner’s Interpersonal-Psychological Theory of Suicidal Behavior (e.g., higher tolerance, habituation to pain). Based on the nearly significant interaction and main effect of weight for pain threshold and tolerance, the findings of this investigation seem to support Joiner's theory of suicide rather than the theory of central sensitization. Continuous or repetitive 
experiences of physical pain have been shown to decrease pain experienced and therefore increase pain tolerance (LeBlanc \& Potvin, 1966; Strempel, 1976; Strempel 1978). Some emotional pain participants did report experiencing past acute and chronic pain; however, the positive life event group did as well and there were no significant differences between the two groups. Because the emotional pain, positive life event, and chronic pain groups had statistically similar characteristics, the possible difference found in pain threshold and with pain tolerance is strengthened. The emotional pain group’s higher pain threshold and tolerance in response to higher intensity pain stimuli means that it may be possible to habituate to physical pain via emotionally distressing experiences.

Currently, Joiner's interpersonal-psychological theory of suicidal behavior suggests that individuals' who commit suicide consciously and/or unconsciously expose themselves to painful stimuli over time. The purpose of these exposures is to habituate one's self to pain to eventually be capable of enduring the pain involved with taking one’s own life (2005). It has been established that enduring repeated stimulation of physical pain in the present decreases experienced pain (LeBlanc \& Potvin, 1966; Strempel, 1976; Strempel 1978). The current findings suggest that in addition to physical pain, enduring emotional pain in the present may increase pain tolerance in the future. This discovery means it may be important to evaluate an individual's emotional pain history, in addition to other factors, when assessing for suicidality.

\section{Exploratory Analyses}

Because the interactions between weight and group membership were on the cusp of being statistically significant, including the participants that could not be matched was hoped to clarify the results. The significant interaction between weight and group membership for pain tolerance is a promising finding. Interestingly, the emotional pain and positive life event groups 
did not differ on their self-reported symptoms of depression and anxiety, but did differ behaviorally. The emotional pain group demonstrated higher pain tolerance compared to the positive life event group. The interaction remains significant with the inclusion of possible covariates (e.g., ASI, BDI-II). This result suggests that with the inclusion of additional participants, the results could be solidified, indicating support for Joiner’s theory.

\section{Limitations}

Inducing pain in the laboratory. One of the limitations inherent in all laboratory pain studies involves problems associated with pain induction in an artificial setting. As such, there are problems with the ecological validity of the pain task. While experiencing pressure pain is a natural sensation, it is not inflicted via a Lucite blade placed on the second phalanx in the "real world.” It is difficult to produce a valid and reliable pain experience across all participants. These problems are common with artificial pain induction because of the many facets of pain perception. Individual differences including past pain experiences and gender influence an individual’s nociceptive experience. While participants were asked to refrain from using pain relievers, this information was not assessed on the day of participation. Therefore, it could be possible that some participants did not follow the instructions. In addition, participants were aware that we were not inflicting pain that could cause serious damage. They also were in control of when the stimulation ended. Research has shown that perceived control of pain stimulation mediates the pain experience, which may lead to an increased pain tolerance (Weisenberg, 1988). Qualitatively, when participants from the emotional pain group commented on the experiment, they often said the pain induction was not "intense” enough; however, individuals' from the positive life event group often remarked that the pain was "too intense." 
Order effects. The order of weight and finger used was counterbalanced across all participants; however, the same finger was consistently matched to the same weight. The primary purpose of this matching was to maintain consistency with the procedure utilized in Sorrell (2000). In addition, the sample size needed to assess for order effects for both condition and finger was outside the scope of the current investigation. In the future, counterbalancing the weight used on each finger would be useful.

Threshold issues. The present study asked participants to touch a yield sign when the pressure stimulation changed from being uncomfortable to being painful in order to assess pain threshold. Based on this description, as soon as the participant felt any pain above a zero on the rating scale, the yield sign should have been touched. Unfortunately, the participants’ responding was not consistent across conditions in both the emotional pain and positive life event groups. Participants often appeared to "forget” to touch the sign or were unsure when the sensation became painful. This inattention to threshold may be because individuals often do not pay specific attention to their own pain threshold, in every day life. Thus, identifying it may be a skill that requires practice. Because the threshold variable likely has reliability and validity issues, the analyses should be interpreted with caution.

Participant self-selection. Another limitation of the current investigation was participant self-selection. Currently, there is no reliable measure to assess the intensity of emotional pain or how significant it may be to an individual. Because of this lack of information, recruitment of emotional pain participants was based on an individual's own opinion of their experiences. All participants reported having experiences with emotional and positive life events. The difference between those who identified themselves as emotional pain participants and those who did not seemed to be the intensity or uniqueness of the emotional pain experience. Based on the 
qualitative evidence, it appeared as though the emotional pain participants had experienced something outside of the realm of "normal” (e.g., long term sexual abuse, murder / suicide of a loved one). Currently, this conclusion is speculative based on the researchers' experiences with the present sample.

Small sample size/lack of diversity. Although using a community sample was a particular strength of this study, it is difficult to obtain a large sample size. The small number of participants is a limitation to the robustness of the findings, and the analyses would benefit from a larger sample. Another limitation related to the community sample was the lack of diversity in participants. The study could benefit from inclusion of different races and ethnicities as the sample was 100\% Caucasian; however, this limitation nearly is consistent with the racial profile of West Virginia (i.e., 95\% Caucasian, 5\% other; U.S. Census Bureau, 2010).

\section{Future Research}

Because the study of emotional pain is a growing area of interest, there are many opportunities to expand on the current research. Based on the findings of the current investigation, examining the presence of emotional pain in a population of individuals' who have attempted suicide or are suicidal could reinforce the relations between emotional pain and suicidality. Orbach, Mikulincer, King, Cohen, and Stein found that inpatient suicidal adolescents exhibited higher pain threshold and tolerance as compared to inpatient nonsuicidal adolescents and control participants (1997). A similar study conducted with an adult population would be beneficial. Future studies of pain induction would benefit from measuring pain in a natural setting, perhaps a dental office or during a medical procedure. This change would allow for greater ecological validity of the findings. Additionally, utilizing a larger and more diverse sample for emotional pain studies would provide more generalizable findings to different cultural 
groups. It is possible that emotional pain experiences have varying effects in different cultures. Because pain perception is a multidimensional concept, there could be contradictory results to the current findings. Another consideration for future research, which currently is underway, is the development of a measure of emotional pain. The creation of a measure that would accurately and reliably identify individuals who have experienced unusual or otherwise chronically life-affecting emotional pain would eliminate problems associated with self-selection.

\section{Conclusions}

The purpose of this study was to examine possible differences and similarities in responses to acute nociception in adults with a significant history of emotional pain, relative to matched samples of chronic pain patients and healthy controls who have had significant positive life experiences. The chronic pain group was found to have significantly higher depression and anxiety symptom scores as compared to the emotional pain group and positive life event group. Mixed between-within subject ANOVAs revealed a significant main effect of weight for pain threshold and tolerance. The interaction between weight and group membership for pain tolerance and threshold both approached significance. These findings indicate that individuals who have experienced emotional pain possibly may have a higher pain threshold and tolerance for more intense pain stimulation as compared to participants reporting positive life events and chronic pain. Exploratory analyses including two addition emotional pain participants encourages the significance of the interaction between weight and group membership. Based on the trend toward higher pain tolerance in individuals’ reporting significant emotional pain events, it appears as though emotional pain experiences may act to habituate an individual to physical pain. This conclusion supports the theory proposed by Joiner (2005) stating individuals who attempt suicide expose themselves to increasingly intense physical pain in order to endure the 
pain necessary to take one's own life. The findings of the current investigation show promise in supporting Joiner's theory of suicide and open a new arena for pain habituation. Thus, experiencing a significant emotionally painful event and the willingness to talk about it, appear to be associated with acute pain habituation. 


\section{References}

Al Absi, M. A., \& Rokke, P. D. (1991). Can anxiety help us tolerate pain? Pain, 46, 43-51. American Psychiatric Association. (2000). Diagnostic and statistical manual of mental disorders ( $4^{\text {th }}$ ed., text revision). Washington, DC: Author.

Arnow, B. A., Blasey, C. M., Lee, J., Fireman, B., Hunkeler, E. M., Dea, R., . . Hayward, C. (2009). Relationships among depression, chronic pain, chronic disabling pain, and medical costs. Psychiatric Services, 60, 344-350.

Bair, M. J., Wu, J., Damush, T. M., Sutherland, J. M., \& Kroenke, K. (2008). Association of depression and anxiety alone and in combination with chronic musculoskeletal pain in primary care patients. Psychosomatic Medicine, 70, 890-897.

Baranauskas, G., \& Nistri, A. (1998). Sensitization of pain pathways in the spinal cord: Cellular mechanisms. Progress in Neurobiology, 54, 349-365.

Bolger, E. (1999). Grounded theory analysis of emotional pain. Psychotherapy Research, 99, 342-362.

Bolles, R. C., \& Fanselow, M. S. (1980). A perceptual-defensive-recuperative model of fear and pain. Behavioral and Brain Sciences, 3, 291-323.

Brown, J. L., Sheffield, D., \& Robinson, M. E. (2003). Social support and experimental pain. Psychosomatic Medicine, 65, 276-283.

Buer, N., \& Linton, S. J. (1999). Fear-avoidance beliefs and catastrophizing: Occurrence and risk factor in back pain and ADL in the general population. Pain, 99, 485-491.

Carr, D. B., \& Goudas, L. C. (1999). Acute pain. Lancet, 353, 2051-2058. 
Cirino, P., Chin, C., Sevcik, R., Wolf, M., Lovett, M., \& Morris, R. (2002). Measuring socioeconomic status: reliability and preliminary validity for different approaches. Assessment, 9, 145-155.

Coffey, G. H., \& Mahon, M. V. (1982). Pain: Theories and a new approach to treatment. Journal of the National Medical Association, 74, 147-153.

Cohen, J. W. (1988). Statistical power analysis for the behavioral sciences ( $2^{\text {nd }}$ ed.). Hillsdale, NJ: Lawrence Erlbaum Associates.

Crombez, G., Vervaet, L., Baeyens, F., Lysens, R., \& Eelen, P. (1996). Do pain expectancies cause pain in chronic low back patients? A clinical investigation. Behaviour Research and Therapy, 34, 919-925.

DeWall, C. N., MacDonald, G.,Webster, G. D., Masten, C. L., Baumeister, R. F., Powell C., Combs, D., Schurtz, D. R., Stillman, T. F., Tice, D. M., \& Eisenberger, N. I. (2010). Acetaminophen reduces social pain: Behavioral and neural evidence. Psychological Science, 21, 931-937.

Eisenberger, N. I., \& Lieberman, M. D. (2004). Why rejection hurts: A common neural alarm system for physical and social pain. TRENDS in Cognitive Sciences, 8, 294-300.

Eisenberger, N. I., Lieberman, M. D., \& Williams, K. D. (2003). Does rejection hurt? An fMRI study of social exclusion. Science, 302, 290-292.

Eisenberger, N. I., Jarcho, J. M., Lieberman, M. D., \& Naliboff, B. D. (2006). An experimental study of shared sensitivity to physical pain and social rejection. Pain, 126, 132-138.

Faul, F., Erdfelder, E., Lang, A. G., \& Buchner, A. (2007). G*Power 3: A flexible statistical power analysis program for the social, behavioral, and biomedical sciences. Behavior Research Methods, 39, 175-191. 
Gaffney, T. J., Foenader, G., Reade, P. C., \& Burrows, G. D. (1987). A study of words used to describe pain. Australian Dental Journal, 32, 326-330. As cited by Sorrell, 2000.

Gracely, R. H., Grant, M. A., \& Giesecke, T. (2003). Evoked pain measures in fibromyalgia. Best Practice and Research Clinical Rheumatology, 17, 593-609.

Grichnik, K., \& Ferrante, F. (1991). The difference between acute and chronic pain. Mount Sinai Journal of Medicine, 58, 217-220.

Haley, W., Turner, J., \& Romano, J. (1985). Depression in chronic pain patients: relation to pain, activity, and sex differences. Pain, 23, 337-343.

Haythornthwaite, J. A., Menefee, L. A., Heinberg, L. J., \& Clark, M. R. (1998). Pain coping strategies predict perceived control over pain. Pain, 77, 33-39.

Hollingshead, A. B. (1975). Four factor index of social status. Unpublished manuscript. Yale University.

Hurtig, I. M., Raak, R. I., Kendall, S. A., Gerdle, B., \& Wahren, L. K. (2001). Quantitative sensory testing in fibromyalgia patients and in healthy subjects: Identification of subgroups. Clinical Journal of Pain, 17, 316-322.

International Association for the Study of Pain Task Force on Taxonomy. (1994). Classification of chronic pain: Descriptions of chronic pain syndromes and definitions of pain terms, ( $2^{\text {nd }}$ ed.; pp. 209-214). Seattle, WA: IASP Press.

Joiner, T. E. (2005). Why people die by suicide. Cambridge, MA: Harvard University Press.

Keppel, G. (1991). Design and analysis: A researcher's handbook. (3 ${ }^{\text {rd }}$ ed.). NJ: Prentice-Hall.

Keppel, G., \& Wickens, T. D. (2004) Design and analysis: A researcher's handbook - Fourth Ed. Upper Saddle River, NJ: Pearson Education, Inc. 
Kosek, E., \& Hansson, P. (1997). Modulatory influence on somatosensory perception from vibration and heterotopic noxious conditioning stimulation (HNCS) in fibromyalgia patients and healthy subjects. Pain, 70, 41-51.

Kremer, E. F., \& Atkinson, J. H. (1984). Pain language: Affect. Journal of Psychosomatic Research, 28, 125-132.

Leary, M. R., Springer, C., Negel, L., Ansell, E., \& Evans, K. (1998). The causes, phenomenology, and consequences of hurt feelings. Journal of Personality and Social Psychology, 74, 12251237.

LeBlanc, J. \& Potvin, P. (1966). Studies on habituation to cold pain. Can J Physiol Pharmacol, 44, 287-293.

MacDonald, G. (2009). Social pain and hurt feelings. In P. Corr \& G. Matthews (Eds.), Cambridge Handbook of Personality Psychology.

MacDonald, G., \& Leary, M. R. (2005). Why does social exclusion hurt?: The relationship between social and physical pain. Psychological Bulletin, 131, 202-223.

McCracken, L. M., Gross, R. T., Aikens, J., \& Carnrike, C., Jr. (1996). The assessment of anxiety and fear in persons with chronic pain: A comparison of instruments. Behaviour Research and Therapy, 34, 927-933.

Mee, S., Bunney, B. G., Reist, C., Potkin, S. G., Bunney, W. E. (2006). Psychological pain: A review of evidence. Journal of Psychiatric Research, 40, 680-690.

Meeus, M., \& Nijs, J. (2006). Central sensitization: A biopsychosocial explanation for chronic widespread pain in patients with fibromyalgia and chronic fatigue syndrome. Clinical Rheumatology, 26, 465-473. 
Melzack, R., \& Casey, K. L. (1968). Sensory, motivational and central control determinants of chronic pain: A new conceptual model. In D. R. Kenshalo (Ed.), The Skin Senses. Springfield, IL: Thomas: 423-443.

Melzack, R. (1975). The McGill Pain Questionnaire: Major properties and scoring methods. Pain, 1, 277-299.

Melzack, R., \& Torgerson, W. S. (1971). On the language of pain. Anesthesiology, 34, 50-59.

Melzack, R., \& Wall, P. D. (1965) Pain mechanisms: A new theory. Science, 150, 971-79.

Merskey, H., Spear F. G. (1967). Pain, psychological and psychiatric aspects. London. Bailliere, Tindall \& Cassell.

Merskey, H., Bogduk, N. (1994). Descriptions of chronic pain syndromes and definitions of pain terms. In Classification of chronic pain, 2nd ed. Seattle: IASP.

Myrtek, M., \& Spital, S. (1986). Psychophysiological response patterns to single, double, and triple stressors. Psychophysiology, 23, 663-671.

Orbach, I. (2003). Mental pain and suicide. Israeli Journal of Psychiatry Related Science, 40, 191-201.

Orbach, I., Mikulincer, M., King, R., Cohen, D., \& Stein, D. (1997). Thresholds and tolerance of physical pain in suicidal and nonsuicidal adolescents. Journal of Consulting and Clinical Psychology, 65, 646-652.

Peterson, R. A., \& Reiss, S. (1992). Anxiety Sensitivity Index Manual ( ${ }^{\text {nd }}$ ed.). Worthington, OH: International Diagnostic Systems.

Price, D. D. (1999). Psychological mechanisms of pain and analgesia. In Progress in pain research and management. Vol. 15. Seattle: IASP Press. 
Price, D. D. (2002, October). Central neural mechanisms that interrelate sensory and affective dimensions of pain. Molecular Interventions, 2(6), 392-403.

Rainville, P. (2002). Brain mechanisms of pain affect and pain modulation. Current Opinion in Neurobiology, 12, 195-204.

Reiss, S., Peterson, R. A., Gursky, M., \& McNally, R. J. (1986). Anxiety, sensitivity, anxiety frequency, and the prediction of fearfulness. Behaviour Research and Therapy, 24, 1-8.

Shear, K. (2003). Complicated grief: A guidebook for therapists. Unpublished Manuscript, Department of Psychiatry, University of Pittsburgh School of Medicine, Pittsburgh, Pennsylvania.

Shneidman, E. S. (1998). Perspectives on suicidology: Further reflections on suicide and psychache. Suicide and Life-Threatening Behavior, 28, 245-250.

Shipton, E. A., \& Tait, B. (2005). Flagging the pain: Preventing the burden of chronic pain by identifying and treating risk factors in acute pain. European Journal of Anaesthesiology, 22, 405-412.

Sorrell, J. T. (2000). Effects of pain and fear stimulus intensity levels on pain responding in chronic pain patients (Unpublished master's thesis). West Virginia University, West Virginia.

Staud, R., \& Smitherman, M. (2002). Peripheral and central sensitization in FM: pathogenic role. Current Pain and Headache Reports, 6, 259-266.

Steer, R. A., Clark, D. A. \& Beck, A. T. (1999). Common and specific dimensions of selfreported anxiety and depression: The BDI-II versus the BDI-IA. Behaviour Research and Therapy, 37, 183-190. 
Stein, M. B., Jang, K. L., \& Livesley, W. J. (1999). Heritability of anxiety sensitivity: A twin study. American Journal of Psychiatry, 156, 246-251.

Strempel, H. (1976). Adaptive modifications of cold pain. Eur J Appli Occup Physiol, 36, 19-25.

Strempel, H. (1978). Adaptive modifications of cold pain. III. Communication: Short-term experiments with 1-min intervals. Eur J Appli Occup Physiol, 39, 63-72.

Turk, D. C., Monarch, E. S., \& Williams, A. D. (2004). Assessment of chronic pain sufferers. In T. Hadjistavropoulous \& K. D. Craig (Eds.), Pain: Psychological perspectives (pp. 209-243). Mahwah, NJ: Lawrence Erlbaum Associates.

U.S. Census Bureau. (2010). State and County Quick Facts. Last Revised: Thursday, 04-Nov2010 12:46:17 EDT. http://quickfacts.census.gov/qfd/states/54000.html.

Vowles, K. E., McNeil, D. W., Sorrell, J. T., \& Lawrence, S. M. (2007). Fear and pain: Investigating the interaction between aversive states. Journal of Abnormal Psychology.

Weinstein, B. (2009). Toward an interview methodology to assess emotional pain. Unpublished manuscript, West Virginia University, West Virginia.

Weinstein, B. \& McNeil, D. (2011). Toward an Understanding of Emotional Pain. Manuscript in preparation, West Virginia University, West Virginia.

Weisenberg, M. (1988). Psychological intervention for the control of pain. Behav Res Ther, 25, 301-312.

Williams, D. (1996). Acute pain management. In D. Gatchel \& D. Turk (Eds.), Psychological approaches to pain management: A practitioner's handbook. (pp. 55-77). NY: Elsevier Science Ltd.

Willis, W. D. J., \& Westlund, K. N. (1997). Neuroanatomy of the pain system and of the pathways that modulate pain. Journal of Clinical Neuropsychology, 14, 2-31. 
Wolfe, F., Smythe, H.A., Yunus, M. B., Bennet, R. M., Bombarier, C., Goldenberg, D. L., . . . Clark, P. (1990). The American college of rheumatology 1990 criteria for the classification of fibromyalgia: Report of the multicenter criteria committee. Arthritis Rheum, 33, 160-172. 


\section{Appendix A}

\section{Morgantown Area Mental Health Resources}

If you desire mental health services after completing the study, here is a list of four resources for mental health services in the Morgantown area, and four crisis/suicide hotlines:

\section{Valley Healthcare System: Crisis Center}

301 Scott Avenue

Morgantown, WV 26508-8804

(304) 225-2280

Website: http://www.valleyhealthcare.org/

Hours: Monday through Friday, 9:00 AM to 5:00 PM

\section{Quin Curtis Center}

Life Sciences Building, Suite 1232

West Virginia University

Morgantown, WV 26506

(304) 293-2001 x 31671

Hours: Monday through Thursday, 9:00 AM to 5:00 PM

\section{Chestnut Ridge Hospital}

930 Chestnut Ridge Road

Morgantown, WV 26505

(304) 598-6400

24 hours-a-day WVU Healthline: 1-800-982-8242

\section{Carruth Center for Counseling and Psychological Services (for WVU students)}

Student Services Center

West Virginia University

Morgantown, WV 26506

(304) 293-4431

Hours: Monday through Friday, 8:15 AM to 4:45 PM

\section{Crisis / Suicide Hotlines}

\section{Valley Healthcare System: Crisis Team}

24 Hour Crisis number: 1-800-232-0020

Suicide Prevention Hotline: 1-800-273-8255

- Hours: 24 hours a day / every day

\section{USA National Suicide Hotlines}

Suicide Prevention Hotline: 1-800-SUICIDE or 1-800-273-TALK

- Toll free and confidential network of more than 140 crisis centers nationwide

- Hours: 24 hours a day / every day 
Appendix B

\section{Acknowledgement of Payment}

Name (print):

Address (print):

City, State, Zip (print):

Social Security Number:

My signature below indicates that I have received $\$ 50.00$ (fifty dollars) in cash in association with my participation in the research study on "Toward an Understanding of Emotional Pain and Joy."

Signature:

Date:

Witness: 
Appendix C

Latin Square

\begin{tabular}{|c|c|}
\hline Weight & Hand / Finger \\
\hline A B C D & W X Y Z \\
\hline C A D B & Y W Z X \\
\hline B D A C & X Z W Y \\
\hline D C B A & Z Y X W \\
\hline A D B C & W Z X Y \\
\hline B A C D & X W Y Z \\
\hline D C A B & Z Y W X \\
\hline C B D A & Y X Z W \\
\hline A C D B & W Y Z X \\
\hline D A B C & Z W X Y \\
\hline C B A D & Y X W Z \\
\hline B D C A & X Z Y W \\
\hline A C B D & W Y X Z \\
\hline B A D C & X W Z Y \\
\hline C D A B & Y Z W X \\
\hline D B C A & Z X Y W \\
\hline
\end{tabular}
A = Blue, Light Weight (LF, LW)
$\mathrm{W}=$ Right, Ring Finger
$\mathrm{B}=$ Blue, Heavy Weight (LF, HW)
$\mathrm{X}=$ Right, Middle Finger
C = Red, Light Weight (HF, LW)
$\mathrm{Y}=$ Left, Ring Finger
$\mathrm{D}=$ Red, Heavy Weight (HF, HW)
$\mathrm{Z}=$ Left, Middle Finger 


\section{Appendix D}

$\underline{\text { ASI }}$

INSTRUCTIONS: Circle the one number that best represents the extent to which you agree with the item. If any of the items concern something that is not part of your experience (e.g., "it scares me when I feel shaky" for someone who has never trembled or had the "shakes"), answer on the basis of how you might feel if you had such an experience. Otherwise, answer all the items on the basis of your own experience.

\begin{tabular}{|c|c|c|c|c|c|c|}
\hline & & Very Little & $\begin{array}{c}\text { A } \\
\text { Little }\end{array}$ & Some & Much & $\begin{array}{l}\text { Very } \\
\text { Much }\end{array}$ \\
\hline 1. & It is important to me not to appear nervous. & $\mathbf{0}$ & 1 & 2 & 3 & 4 \\
\hline 2. & $\begin{array}{l}\text { When I cannot keep my mind on a task, I worry that I } \\
\text { might be going crazy. }\end{array}$ & $\mathbf{0}$ & 1 & 2 & 3 & 4 \\
\hline 3. & It scares me when I feel "shaky" (trembling). & $\mathbf{0}$ & 1 & 2 & 3 & 4 \\
\hline 4. & It scares me when I feel faint. & $\mathbf{0}$ & 1 & 2 & 3 & 4 \\
\hline 5. & $\begin{array}{l}\text { It is important to me to stay in control of my } \\
\text { emotions. }\end{array}$ & $\mathbf{0}$ & 1 & 2 & 3 & 4 \\
\hline 6. & It scares me when my heart beats rapidly. & $\mathbf{0}$ & 1 & 2 & 3 & 4 \\
\hline 7. & It embarrasses me when my stomach growls. & $\mathbf{0}$ & 1 & 2 & 3 & 4 \\
\hline 8. & It scares me when I am nauseous. & $\mathbf{0}$ & 1 & 2 & 3 & 4 \\
\hline 9. & $\begin{array}{l}\text { When I notice that my heart is beating rapidly, I } \\
\text { worry that I might have a heart attack. }\end{array}$ & $\mathbf{0}$ & 1 & 2 & 3 & 4 \\
\hline 10. & It scares me when I become short of breath. & $\mathbf{0}$ & 1 & 2 & 3 & 4 \\
\hline 11. & $\begin{array}{l}\text { When my stomach is upset, I worry that I might be } \\
\text { seriously ill. }\end{array}$ & $\mathbf{0}$ & 1 & 2 & 3 & 4 \\
\hline 12. & $\begin{array}{l}\text { It scares me when I am unable to keep my mind on a } \\
\text { task. }\end{array}$ & $\mathbf{0}$ & 1 & 2 & 3 & 4 \\
\hline 13. & Other people notice when I feel shaky. & $\mathbf{0}$ & 1 & 2 & 3 & 4 \\
\hline 14. & Unusual body sensations scare me. & $\mathbf{0}$ & 1 & 2 & 3 & 4 \\
\hline 15. & $\begin{array}{l}\text { When I am nervous, I worry that I might be mentally } \\
\text { ill. }\end{array}$ & $\mathbf{0}$ & 1 & 2 & 3 & 4 \\
\hline 16. & It scares me when I am nervous. & $\mathbf{0}$ & 1 & 2 & 3 & 4 \\
\hline
\end{tabular}




\section{Appendix E}

Verbal Fear Intensity Instructions

\section{*High fear intensity instructions}

Over the next few minutes you will have your finger in this pressure device. You will likely experience this pain as agonizing and horrible. Although you may experience this pain, the stimulation will not produce any lasting physical damage to your skin or any part of your body. You may consider this pounding sensation to be an excruciating and unbearable experience, producing a high level of anxiety.

*Low fear intensity instructions

Over the next few minutes you will have your finger in this pressure device. You will likely experience this pain as mild and annoying. Although you may experience this pain, the stimulation will not produce any lasting physical damage to your skin or any part of your body. You may consider this pressing sensation as a tiring and discomforting experience, producing a low level of anxiety.

*Neutral fear intensity instructions

Do your best to endure any pain you may experience for the duration of this condition. If at any point you become too uncomfortable to continue, please remember that you are permitted to stop at any time by placing your hand on the red "Stop" sign in front of you.

Over the next few minutes you will have your finger in this pressure device. Although you may experience some pain, the stimulation will not produce any lasting physical damage to your skin or any part of your body.

*Note: Above taken from Sorrell, 2000a 
Appendix F

Emotional Pain Advertisement

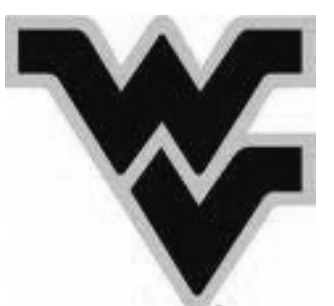

\section{WVU Researchers seek to learn more about Emotional "Pain" \\ (from any event that has caused heartbreak, sadness, loss, or any distress that is experienced painfully)}

Participation involves interviews and talking about previous life experiences, both negative and positive, completing surveys, and taking part in a task with potentially painful finger pressure (which you can stop at any time)

Financial compensation provided for time and travel to WVU's downtown campus (with free parking)

Takes about 2 hours

Must be at least 18 years old

Call (304) 685-5501 for more information or to sign up 
Appendix G

Positive Life Event Advertisement

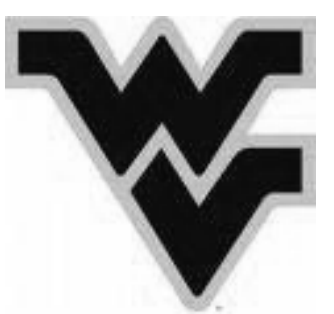

WVU Researchers

seek to learn more about

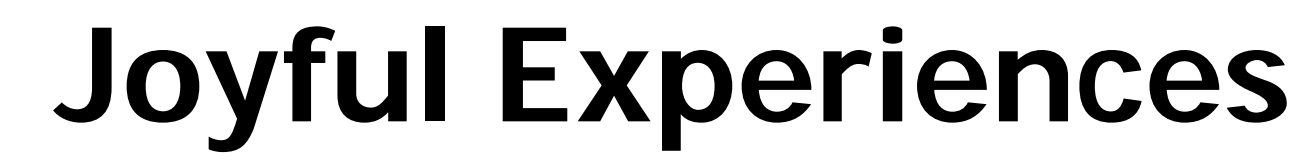

(from any event that has caused happiness, contentment, satisfaction, or feeling gratified)

Participation involves interviews and talking about previous life experiences, both positive and negative, completing surveys, and taking part in a task with potentially painful finger pressure (which you can stop at any time)

Financial compensation provided for time and travel to WVU's downtown campus (with free parking)

\section{Takes about 2 hours}

Must be at least 18 years old

Call (304) 685-5501 for more information or to sign up

IRB Approval on file Daniel W. McNeil, PhD: Principal Investigator Department of Psychology Eberly College of Arts \& Sciences West Virginia University 
Appendix $\mathrm{H}$

Phone Screening Form

\section{Toward an Understanding of Emotional Pain and Joy}

\section{Telephone Screening Script}

Name of caller: Name of Researcher:

Hello Emotions Project, my name is . I'm in the department of Psychology at West Virginia University. Thank you for calling to find out more about our research project.

We are working on a research study about emotional pain and joy. Specifically, we are interested in how individuals experience emotional pain, how they cope with it, how it changes over time, and how that influences their pain tolerance and threshold. We also are interested in positive experiences, how people experience joy, remember it, and how they recall it over time.

As part of our study, we will be asking you to participate in two interviews, one on an emotionally painful experience and the other on a joyful experience. We will also ask you to complete a few short questionnaires prior to participating in a pressure pain task in which you can stop at any time. That task involves pressure on four of your fingers. Again, you can stop that pressure at any time you wish. What else would you like me to tell you about this study?

Do you think you might be interested in participating in this study?

$<$ If NO $>$ Thank you very much for calling.

$<$ If YES $>$ Prior to enrolling you in the study, we have to ask you a few questions to determine if you are eligible. We will be collecting information about you during this phone call and your taking part in this phone call is completely voluntary.

Your information will only be seen by researchers at West Virginia University associated with our project. We try to make sure that the information we collect from you is kept private and used only for the research study we are discussing.

That being said, I would like to ask you a series of questions. Please answer honestly and to the best of your ability. There is a possibility that some of the questions may make you uncomfortable or distressed; if so please let me know. Remember, your participation is voluntary; you do not have to complete these questions.

Do I have your permission to ask you these questions? 
1) How did you hear about this study? (what was the name of the study on the advertisement)?

(Circle One) Emotional Pain Ad Positive Life Experience

2) Emotional pain is felt in response to psychological suffering that is associated with a distressing life situation, in which may occur in the absence of physical pain.

a) Have you ever had a time that you felt emotional pain in an intense way that was out of the ordinary? I am referring to emotional pain that would be significant enough that you should be able to remember it if it happened at any time in your life.

YES NO

b) How intense would you rate your most extreme experience of Emotional Pain on a scale of $0-100$, with " 0 " being not at all intense, and " 100 " being extremely intense?

c) Please briefly summarize what happened that led to your_emotional pain experience:

3) A positive life experience is felt in response to happy events, in which there is delight, satisfaction, gladness, and/or being elated.

a) Have you ever had a time that you felt a positive life experience in an intense way that was out of the ordinary? I am referring to a positive life experience that would be significant enough that you should be able to remember it if it happened at any time in your life.

YES NO

b) How intense would you rate your most extreme Positive Life Experience on a scale of 0 - 100, with "0" being not at all intense, and " 100 " being extremely intense?

c) Please briefly summarize what happened that led to your_joyful experience: 
Now, I would like to ask you a few general questions about yourself.

1) 1a. Age:

1b. Date of birth:

2) Gender: MALE FEMALE

3) (If FEMALE) Are you currently pregnant, or believe you might be pregnant? YES NO

4) What is your current marital status? Are you currently: single / married / separated or divorced / widowed / live in partner?

5) What is your current occupation, and your past occupations?

6) If spouse or live-in partner or parents/caregivers: What are the current and past occupations of your spouse, live-in partner, or parents/caregivers?

7) Are you currently employed? Full-time, part-time, retired, disabled?

8) What is the highest level of education you have obtained? Specifically, how many years of education have you completed?

9) Now I'm going to ask you a question about how you see yourself compared to other people:

Imagine a ladder with 10 rungs, with each of the 10 rungs being numbered. The top rung is labeled with the number "10", the rung second from the top is labeled " 9 ", and each lower rung has a smaller number, with the bottom rung labeled " 1 ".

Think of this ladder as representing where people stand in the United States. At the TOP of the ladder are the people who are best off - those who have the most money, the most education, and the most respected jobs.

At the BOTTOM are the people who have the least money, least education, and the least respected jobs or no job. The higher up you are on this ladder, the closer you are to the people at the very top; the lower you are, the closer you are to the people at the very bottom.

WHERE WOULD YOU PLACE YOURSELF ON THIS LADDER? What is the number of the rung where you think you stand at this time in your life, relative to other people in the United States? 


\section{0) PAIN/ MEDICAL CONDITIONS}

a) Are you currently experiencing any pain that has lasted for four months or longer?

b) Are you currently experiencing any significant acute pain?

c) Do you currently have any heart problems?

d) Do you currently use a morphine pump?

e) Are you missing your ring or middle finger on either hand?

f) Do you have an open wound on either your middle or ring fingers?

g) Do you have peripheral neuropathy? Y / N Polyneuropathy in the upper extremities? Y / $\mathbf{N}$ Reflex sympathetic dystrophy (RSD) in the upper extremities? Y / $\mathbf{N}$

\section{1) MENTAL HEALTH SCREENING}

a) Have you ever seen something that other people who were there could not see? (Not dreaming, not half-asleep, not under the influence of drugs or alcohol) i) If YES, briefly explain:

b) Have you ever heard anything that other people who were there could not hear? I don't mean having good hearing, but rather hearing things that other people said did not exist. (Not dreaming, not half-asleep, not under the influence of drugs or alcohol) i) If YES, briefly explain:

c) Have you ever felt like others could read your mind or that your thoughts were not your own, as if they were put there by someone else? (Not dreaming, not half-asleep, not under the influence of drugs or alcohol)

i) If YES, briefly explain:

d) Have you ever believed that a strange, outside force was communicating specifically with you? Sending you signals that only you could understand? (Not dreaming, not half-asleep, not under the influence of drugs or alcohol)

i) If YES, briefly explain:

e) Do you have any current problems with alcohol or drugs?

i) If YES, briefly explain:

f) Are you currently receiving any medication, counseling, or other treatment for depression, anxiety, or any other mental health concerns?

i) If YES, briefly explain:

g) Do you have any mental health concerns at present?

i) If YES, briefly explain: 


\section{Potential Risks}

No permanent side effects are anticipated. You may become upset after re-experiencing past emotionally painful situations and/or experience slight discomfort during exposure to the pressure pain task. These sensations are expected to disappear quickly (i.e., within 60 seconds) when the stimulation is discontinued. At the site of stimulation there is likely to be a small indentation in the skin that may last for approximately 30 minutes.

\section{Potential Benefits}

You may gain a better understanding of the research process and your participation may eventually benefit others. Additionally, recounting personally relevant emotional topics has been demonstrated to have a wide range of mental and physical benefits. It is believed that describing an emotional experience helps make sense of the experience, as well as relieving stress from disclosure, which is commonly referred to as "getting something off your chest". You may also benefit from having questions answered relating to your own pain and fears.

There are no costs for you to participate beyond your own transportation to participate.

If you agree to participate in the study, you will be compensated $\$ 50.00$ at completion of the tasks we discussed.

\section{In closing:}

- What questions do you have?

- Do you think you would like to take part in this research?

$<$ If, NO $>$ Thank you for your time.

$<$ If YES $>$ Thank you for your interest. I would like to schedule a time for you to come in, if that works for you.

If you have any other questions or concerns, please feel free to contact at (304) 685-5501. 


\section{SCHEDULING}

Name:

Phone:(specify:day/evening/cell)

Address:

Time:

Day: Date:

Directions to the Anxiety, Psychophysiology, \& Pain Research Laboratory:

The Anxiety, Psychophysiology, \& Pain Research Laboratory (APP Lab) is located on the second floor of the Life Sciences Building, in room 2317. The street it is located on is Campus Drive, which is in the Sunnyside neighborhood, as a part of West Virginia University's Downtown Campus.

The address of the APP Lab is 53 Campus Drive, Morgantown, WV 26506. It is located in room 2317 of the Life Sciences Building. Turn left down the hallway from the elevator on the second floor of the building, and the clinic is located through a glass door halfway down the hallway on your left. Please call (304)685-5501 if you need further directions.

Free parking is available on Campus Drive. However, for free parking, you need a parking pass to place on your dashboard. You can give me your mailing address now, and I will mail one to you so that you have it ahead of time. But, if you forget, and if you have a cell phone, you can call (304) 685-5501, from the parking space and a parking pass will be brought out to you. Otherwise, you can enter the APP Lab to get a parking pass, and then place it on your dashboard.

\section{DIRECTIONS TO THE APP LAB FROM I-68}

From highway 68, exit at the University Avenue exit. Turn left down the hill on North 119. Continue straight through several lights through town. Route 119 will be called Don Knotts Boulevard and then turn into Beechurst. The road will narrow to 2 lanes. Turn right at the light at Campus Drive and go up the hill. The APP Lab is in the new Life Sciences Building on your right $1 / 2$ way up the block. There are 4 parking spaces in front of the building marked "QUIN CURTIS CENTER” where you may park.

\section{DIRECTIONS TO THE APP LAB FROM I-79}

Take the Westover/Downtown Morgantown exit (exit \#152) and turn towards Morgantown (away from the mall) at the end of the exit ramp. Just after you turn you should pass an Exxon on your right. Drive Northeast on Highway 19 through Westover. This road is fairly curvy; keep following it to the Monongahela River where you will cross a bridge. Cross the bridge in the left lane into downtown Morgantown, turning left at the end of the bridge. You will now be on Beechhurst Street. The road will narrow to 2 lanes. Turn right at the light at Campus Drive and go up the hill. The APP Lab is in the new Life Sciences Building on your right $1 / 2$ way up the block. There are 4 parking spaces in front of the building marked “QUIN CURTIS CENTER” where you may park.

If there are no parking places available, you may park in the lot immediately next to the Life Sciences Building. Just be sure to display the parking pass on your dash. 
Appendix I

Consent Form

\section{WestVirginiaUniversity. \\ Office of Research Compliance}

CONSENT AND INFORMATION FORM

OMR ICF

Principal Investigator: McNeil, Daniel

Department: $\quad$ ARTS \& SCIENCES - Psychology

Tracking Number: $\quad \mathrm{H}-22678$

\section{Study Title:}

Toward an Understanding of Emotional Pain and Joy

\section{Co-Investigator(s):}

Alison Vargovich, BA; Ben Weinstein, MA; Candice Arnwine; Cameron Randall, BS; Suzan Clemens, MA; Grant Shulman; Michelle Harris;

Christina Hamer; Christina Ho; Andrew Myers; and Nathaniel Warman.

\section{Sponsor}

Funding for this project is provided by the Principal Investigator's accounts at West Virginia University.

\section{Contact Persons}

In the event you experience any side effects or injury related to this research or have complaints or questions concerning this research, you should contact Dr. Daniel W. McNeil at 304-293-2001, ext. 31622.

For information regarding your rights as a research subject, you may contact the Office of Research Compliance at 304/293-7073.

\section{Introduction}

In addition if you would like to discuss problems, concerns, have suggestions related to research, or would like to offer input about the research, contact the Office of Research Integrity and Compliance at 304293-7073. 
You, have been asked to participate in this research study, which has been explained to you by . This study is being conducted by Ben Weinstein, M.A., Alison Vargovich, B.A., and Candice Arnwine to partially fulfill the requirements for a doctorate level dissertation, a master's thesis, and a senior honors thesis, in Clinical Psychology in the Department of Psychology at West Virginia University, under the supervision of Daniel W. McNeil, Ph.D.

\section{Purposes of the Study}

The purpose of this study is to understand how emotional pain and joy are felt, how well they can be measured, and how people reporting emotional painful and joyful events experience physical pain. Approximately 68 people will be enrolled at WVU.

\section{Description of Procedures}

This study first involves a short telephone screening to collect information and schedule an appointment. At the in-person appointment, there will be two videotaped interviews which will ask about emotional pain and joyful experiences; more historical information will be collected, and some measures of psychological functioning will be completed. Participants will then take part in a pressure pain task in which they will go through four phases of pain induction and will be asked to rate their pain threshold and tolerance during each one. The entire procedure will last approximately 2 hours. Participants do not have to answer all the questions, and will have the opportunity to see all the materials before signing the consent form.

\section{Risks and Discomforts}

There are no known or expected risks from participation in this study. Temporary anxious thoughts may occur as a result of sharing information during the interview process, and slight physical discomfort may result from exposure to the pressure pain algometer.

\section{Alternatives}

You do not have to participate in this study. 
There are no alternatives available.

\section{Benefits}

There is some evidence that describing past hurtful or negative experiences is beneficial. You also may gain a better understanding about how research is conducted and will benefit from having questions answered relating to your own pain and fears. Additionally, the knowledge gained from this study may eventually benefit others.

\section{Financial Considerations}

There are no special fees for participating, and you will receive $\$ 50.00$ following your participation in the study. The payment will be in the form of either cash, or money order. Psychology students can receive either the $\$ 50.00$ payment or extra class credit for participation. (There are other ways to earn class credit instead of research, such as book reports and campus lectures.)

\section{Confidentiality}

Any information about you that is obtained as a result of your participation in this research will be kept as confidential as legally possible. Your research records and test results, just like hospital records, may be subpoenaed by court order or may be inspected by federal regulatory authorities without your additional consent. In addition, there are certain instances where the researcher is legally required to give information to the appropriate authorities. These would include mandatory reporting of infectious diseases, mandatory reporting of information about behavior that is imminently dangerous to you or to others, such as suicide, child abuse, etc. In any publications that result from this research, neither your name nor any information from which you might be identified will be published without your consent. Videotapes will be kept locked up and will be destroyed as soon as possible after the research is finished. In any publications that result from this research, neither your name nor any information from which you might be identified will be published without your consent. We know that information about you and your health is private. We are dedicated to protecting the privacy of that information. Because of this promise, we must get your written authorization (permission) before we may use or disclose your protected health information or share it with others for research purposes. You can 
decide to sign or not to sign this authorization section. However, if you choose not to sign this authorization, you will not be able to take part in the research study. Whatever choice you make about this research study, it will not have an effect on you status at West Virginia University. You may cancel this authorization at any time by writing to the Principal Investigator: Daniel W. McNeil, Ph.D., Box 6040, Department of Psychology, West Virginia University, Morgantown, WV 26506-6040.If you cancel this authorization, any information that was collected already for this study cannot be withdrawn. Once information is disclosed, according to this authorization the recipient may redisclose it and then the information may no longer be protected by federal privacy regulations. This authorization will not expire unless you cancel it.

\section{SIGNATURE}

I have read this section and all of my questions have been answered. By signing below, I acknowledge that I have read and accept all of the above.

Signature of Subject or Authorized Representative Date

Print Name of Subject or Authorized Representative

\section{Voluntary Participation}

Participation in this study is voluntary. You are free to withdraw your consent to participate in this study at any time. Refusal to participate or withdrawal will not affect your future care, [or your employee status at West Virginia University or your class standing or grades, as appropriate] and will involve no penalty to you. In the event new information becomes available that may affect your willingness to participate in this study, this information will be given to you so that you can make an informed decision about whether or not to continue your participation. You have been given the opportunity to ask questions about the research, and you have received answers concerning areas you did not understand. 
Upon signing this form, you will receive a copy.

I willingly consent to participate in this research.

The participant has had the opportunity to have questions addressed. The participant willingly agrees to be in the study.

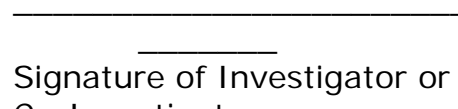

Co-Investigator

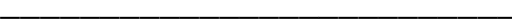

Printed Name

\section{Date Time}




\section{Appendix J}

\section{Demographics Form}

NAME:

\section{Age}

How old are you?

\section{Ethnicity / Race}

What is your race or ethnicity?

\section{Education Level}

What is the highest level of education you completed?

\section{Romantic Relationship Status}

Single (no current romantic partner)

Married/Live with current partner

Current partner lives outside the home

Separated / Divorced / Widowed

\section{Current Employment Status}

Full-time employment

Part-time employment

Unemployed

Disabled

Volunteer

$\square$ Other:

\section{Current Occupation}

\begin{tabular}{ll}
$\square$ & Not applicable (N/A) \\
\hline$\square$ & Student \\
\hline$\square$ & Skilled trade \\
\hline$\square$ & Unskilled trade \\
\hline$\square$ & Homemaker \\
\hline$\square$ & Professional (specify: \\
\hline$\square$ & Other:
\end{tabular}

7. What is your (combined) annual household income (before taxes)?

$\square \$ 0-20,000 \square \$ 20-40,000 \square \$ 40-60,000$
$\square \$ 60-80,000 \square \$ 80-100,000 \square \$ 100,000+$

Today's date:

8. Are you undergoing any current counseling or other outpatient treatment for emotional or psychological problems?

$\square$ Yes $\square$ No

9. Have you ever had any previous counseling or other outpatient treatment for emotional or psychological problems?

$\square$ Yes $\square$ No

10. Have you ever been hospitalized for emotional or psychological problems?

$\square$ Yes $\square$ No

11. Are you currently taking any medications?

$\square$ Yes $\square$ No

If "Yes", please specify your medication(s) and dosage _\# times taken per day here:

12. Do you have any current or past significant medical conditions?

$\square$ Yes $\square$ No

If “Yes”, please specify your significant current or past medical condition(s) here: 


\section{Appendix K}

\section{Brief Description of the algometer and Procedures to Participants}

As you remove the algometer from the materials box, indicate to the participant the following:

“This is an algometer pressure device. It will be used to produce a pressure sensation on four of your fingers (hold up your middle and ring finger on each hand as you say this) through the course of what we do here today. First, we place your hand on this wooden platform, with one of your fingers between these two small pieces of wood. These screws will be gently tightened to prevent your finger from moving (point to the screws as you say these words). Your other fingers will rest on top of the screws that will keep your one finger in place.”

"Next, I will put this small wooden platform over your finger. Go ahead and feel this piece of plastic that will be touching the top of your finger (let the participant feel the plastic piece). Then, I will gently place a weight on the top of this platform. At some point, the pressure may become too painful. If it does become painful, touch this yellow sign (point to the yellow "painful" sign). If the pressure becomes too painful and you want to stop, touch this red "Stop" sign (point to the red "stop" sign). Do not worry about trying to withstand any pain you may experience, just act as naturally as possible. When the pressure begins to hurt, touch the yellow sign. When you want to stop because the pressure is too painful to continue, touch the red sign.”

"What questions do you have about the algometer or the procedure just explained to you?” 
Table 1.

Total Number/Means (and Percentage/Standard Deviations) for Demographic Characteristics

Emotional Pain $\quad$ Positive Life Event Chronic Pain

Gender

Female

$9(\%)$

9

9

Male

5

5

5

Age

50.5 (15.5)

50.6 (14.8)

48.6 (9.8)

Hollingshead SES

$50.1(10.2)$

46.0 (10.1)

41.8 (8.7)

Class of SES

Class I (55-66)

6 (43.0\%)

3 (21.4\%)

2 (14.3\%)

Class II (40-54)

$6(43.0 \%)$

$8(57.1 \%)$

7 (50.0\%)

Class III (30-39)

2 (14.3\%)

$3(21.4 \%)$

4 (28.6\%)

Class IV (20-29)

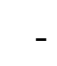

$1(7.1 \%)$

Class V (8-19)

Note. The Class of SES categories are guidelines based on the Hollingshead measure of SES. 
Table 2.

Exclusionary Criteria

1. Heart Disease

2. Peripheral Neuropathy or polyneuropathy in the upper extremities

3. Reflex sympathetic dystrophy (RSD) in the upper extremities

4. Missing middle or ring finger on either hand

5. Use of morphine pump

6. Under age 18 years

7. Over age 70 years

8. Open wound on either middle or ring fingers

9. Not literate in spoken and written English

10. Obviously inebriated

11. Demonstrating obvious psychotic symptoms

12. Developmentally disabled

13. Currently pregnant

14. Reporting significant chronic or acute pain 


\section{Table 3.}

Means (and Standard Deviations) for additional events and intensity ratings

\begin{tabular}{lcc}
\hline & Emotional Pain & Positive Life Event \\
\hline Additional emotional pain events & $3.5(1.6)$ & $2.4(1.3)$ \\
Additional positive life events & $2.6(1.3)$ & $4.4(3.4)$ \\
Intensity rating ${ }^{\mathrm{a}}$ emotional pain & $83.2(31.4)$ & $94.7(9.1)$ \\
Intensity rating & \\
\end{tabular}

Note. $n=14$ per group; ${ }^{\mathrm{a}}=$ immediately following emotional pain event; ${ }^{\mathrm{b}}=$ immediately following positive life event. 
Table 4.

Means (and Standard Deviations) for the ASI and BDI-II across groups

\begin{tabular}{lcccc}
\hline & Emotional Pain & Positive Life Event & Chronic Pain & Total \\
\hline ASI & $18.3(10.1)^{\mathrm{a}}$ & $18.5(7.6)^{\mathrm{a}}$ & $29.2(13.1)^{\mathrm{b}}$ & $22.0(11.5)$ \\
BDI-II & $9.9(5.6)^{\mathrm{a}}$ & $4.8(5.0)^{\mathrm{a}}$ & $26.4(10.1)^{\mathrm{b}}$ & $13.7(11.7)$ \\
\hline
\end{tabular}

Note. $n=14$ per group; Means of groups within each row that do not share a common superscript differ at $p<.05$. 
Table 5.

Threshold across conditions: Mean (Standard Deviation)

\begin{tabular}{|c|c|c|c|c|}
\hline \multirow[t]{2}{*}{ Conditions } & \multicolumn{3}{|c|}{ Groups } & Total \\
\hline & Emotional Pain & Positive Life Event & Chronic Pain & \\
\hline $\begin{array}{c}\text { Low Fear/Low } \\
\text { Weight }\end{array}$ & 139.9 (129.5) & 151.9 (126.9) & $37.2(38.6)$ & 109.7 (116.6) \\
\hline Range & 297 & 297 & 119 & 299 \\
\hline $\begin{array}{c}\text { Low Fear/High } \\
\text { Weight }\end{array}$ & $86.0(119.0)$ & $44.9(79.6)$ & $14.6(12.3)$ & 48.5 (86.2) \\
\hline Range & 298 & 297 & 29 & 299 \\
\hline $\begin{array}{c}\text { High Fear/Low } \\
\text { Weight }\end{array}$ & $128.7(134.0)$ & $111.6(119.0)$ & 51.9 (67.3) & $97.4(112.8)$ \\
\hline Range & 295 & 293 & 239 & 299 \\
\hline $\begin{array}{c}\text { High Fear/High } \\
\text { Weight }\end{array}$ & $61.0(107.5)$ & $38.1(78.6)$ & $18.1(14.9)$ & 39.1 (77.5) \\
\hline Range & 299 & 299 & 42 & 299 \\
\hline
\end{tabular}

Note. $n=14$ per group; threshold is measured in seconds. 
Table 6.

Pain tolerance across conditions: Mean (Standard Deviation)

\begin{tabular}{|c|c|c|c|c|}
\hline \multirow[t]{2}{*}{ Conditions } & \multicolumn{3}{|c|}{ Groups } & \multirow[t]{2}{*}{ Total } \\
\hline & Emotional Pain & Positive Life Event & Chronic Pain & \\
\hline $\begin{array}{c}\text { Low Fear/Low } \\
\text { Weight }\end{array}$ & 207.2 (120.5) & $191.2(112.6)$ & 225.9 (100.2) & 208.1 (109.6) \\
\hline Range & 293 & 294 & 260 & 294 \\
\hline $\begin{array}{c}\text { Low Fear/High } \\
\text { Weight }\end{array}$ & $182.1(130.0)$ & 131.7 (118.1) & $120.4(122.0)$ & 144.7 (123.5) \\
\hline Range & 296 & 289 & 289 & 296 \\
\hline $\begin{array}{c}\text { High Fear/Low } \\
\text { Weight }\end{array}$ & 216.2 (120.3) & 191.3 (119.3) & 200.1 (110.7) & 202.5 (114.4) \\
\hline Range & 294 & 281 & 283 & 294 \\
\hline $\begin{array}{c}\text { High Fear/High } \\
\text { Weight }\end{array}$ & 166.7 (136.8) & 75.5 (89.1) & $116.1(124.0)$ & 119.4 (121.5) \\
\hline Range & 297 & 292 & 293 & 297 \\
\hline
\end{tabular}

Note. $n=14$ per group; tolerance is measured in seconds. 
Table 7.

Mixed between-subjects ANOVA: Pain Threshold

\begin{tabular}{|c|c|c|c|c|c|c|}
\hline Source & $\underline{S S}$ & $\underline{d f}$ & $\underline{M S}$ & $\underline{F}$ & $\underline{p}$ & $\underline{\text { Partial }}^{\underline{2}}$ \\
\hline$\overline{\text { GROUP }}$ & 165234.14 & 2 & 82617.07 & 3.13 & .06 & .14 \\
\hline BETWEEN ERROR & 1029724.27 & 39 & & & & \\
\hline INSTRUCTIONS & 4940.00 & 1 & 4940.00 & 1.62 & .21 & .04 \\
\hline WEIGHT & 150062.15 & 1 & 150062.15 & 35.46 & .001 & .48 \\
\hline INSTRUC. * GROUP & 8566.33 & 2 & 4283.17 & 1.41 & .26 & .07 \\
\hline INSTRUC. * WEIGHT & 81.48 & 1 & 81.48 & .03 & .87 & .00 \\
\hline GROUP * WEIGHT & 26931.05 & 2 & 13465.52 & 3.18 & .05 & .14 \\
\hline \multicolumn{7}{|l|}{ INSTRUC. * GROUP * } \\
\hline WEIGHT & 4918.19 & 2 & 2459.14 & .86 & .43 & .04 \\
\hline
\end{tabular}


Table 8.

Mixed between-subjects ANOVA: Pain Tolerance

\begin{tabular}{lcccccc}
\hline Source & $\underline{S S}$ & $\underline{d f}$ & $\underline{M S}$ & $\underline{F}$ & $\underline{p}$ & $\underline{\text { Partial }^{2}}$ \\
\hline GROUP & 59093.80 & 2 & 29546.90 & .66 & .52 & .03 \\
BETWEEN ERROR & 1749835.11 & 39 & & & & \\
INSTRUCTIONS & 9997.71 & 1 & 9997.71 & 3.15 & .08 & .08 \\
WEIGHT & 225280.38 & 1 & 225280.38 & 44.74 & .001 & .53 \\
INSTRUC. * GROUP & 4348.82 & 2 & 2170.41 & .69 & .51 & .03 \\
INSTRUC. * WEIGHT & 4080.86 & 1 & 4080.86 & 1.82 & .19 & .05 \\
GROUP * WEIGHT & 27443.73 & 2 & 13721.86 & 2.73 & .08 & .12 \\
INSTRUC. * GROUP * & & & & & & .11 \\
WEIGHT & 10701.75 & 2 & 5350.88 & 2.39 & .11 & \\
\hline
\end{tabular}


Table 9.

Number of participants who reached maximum tolerance across conditions

\begin{tabular}{cccc}
\hline Condition & Groups & \\
& Emotional Pain & Positive Life Event & Chronic Pain \\
\hline Low Fear/Low Weight & 8 & 6 & 7 \\
Low Fear/High Weight & 7 & 3 & 4 \\
High Fear/Low Weight & 9 & 7 & 4 \\
High Fear/High Weight & 6 & 1 & 22 of 56 \\
Total & 30 of 56 & 17 of 56 & \\
\hline
\end{tabular}

Note. There were 14 participants in each of the conditions and group pairings. 
Figure 1

Threshold and Tolerance Signs

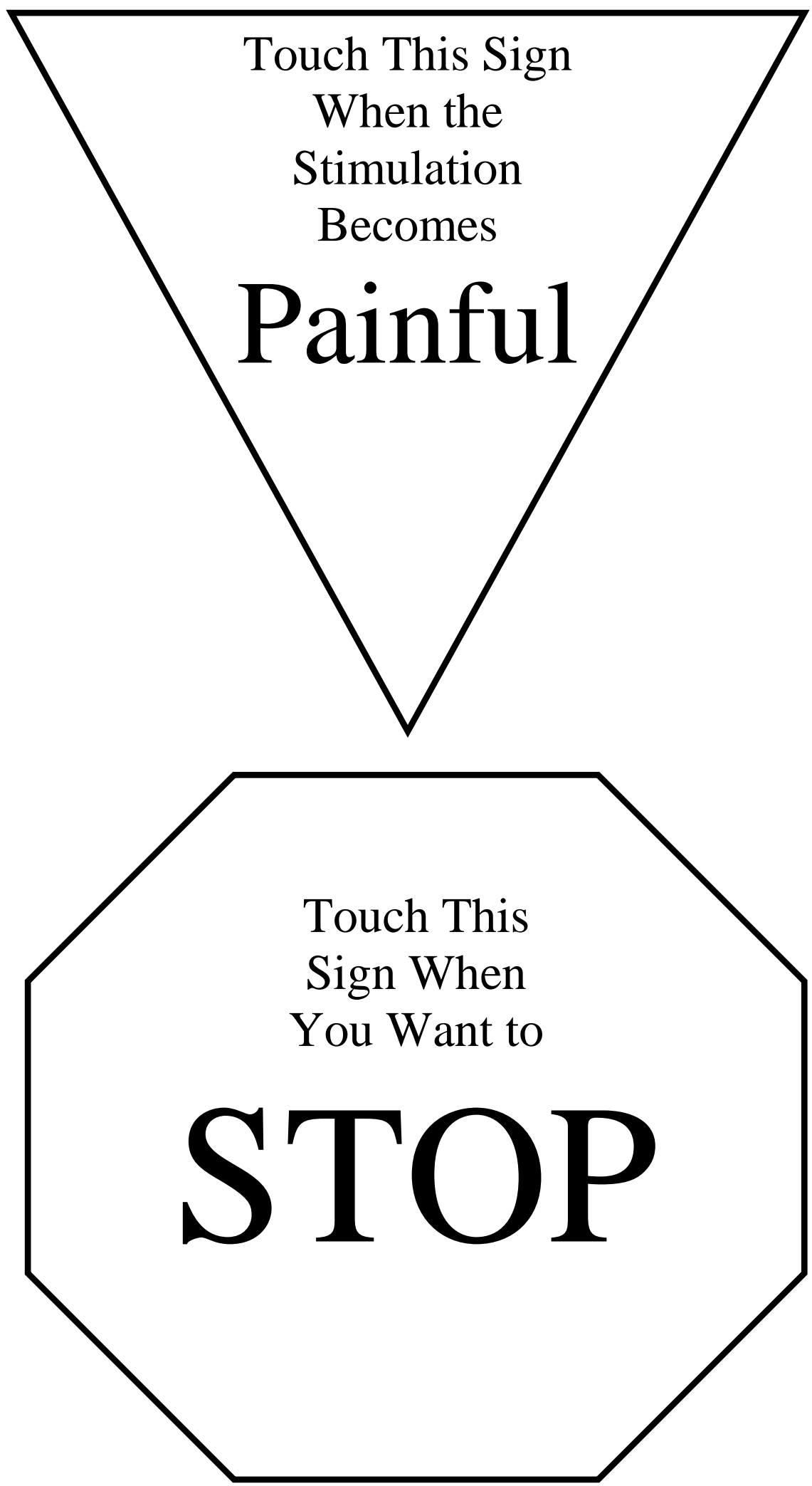


Figure 2

Procedural Flow Chart

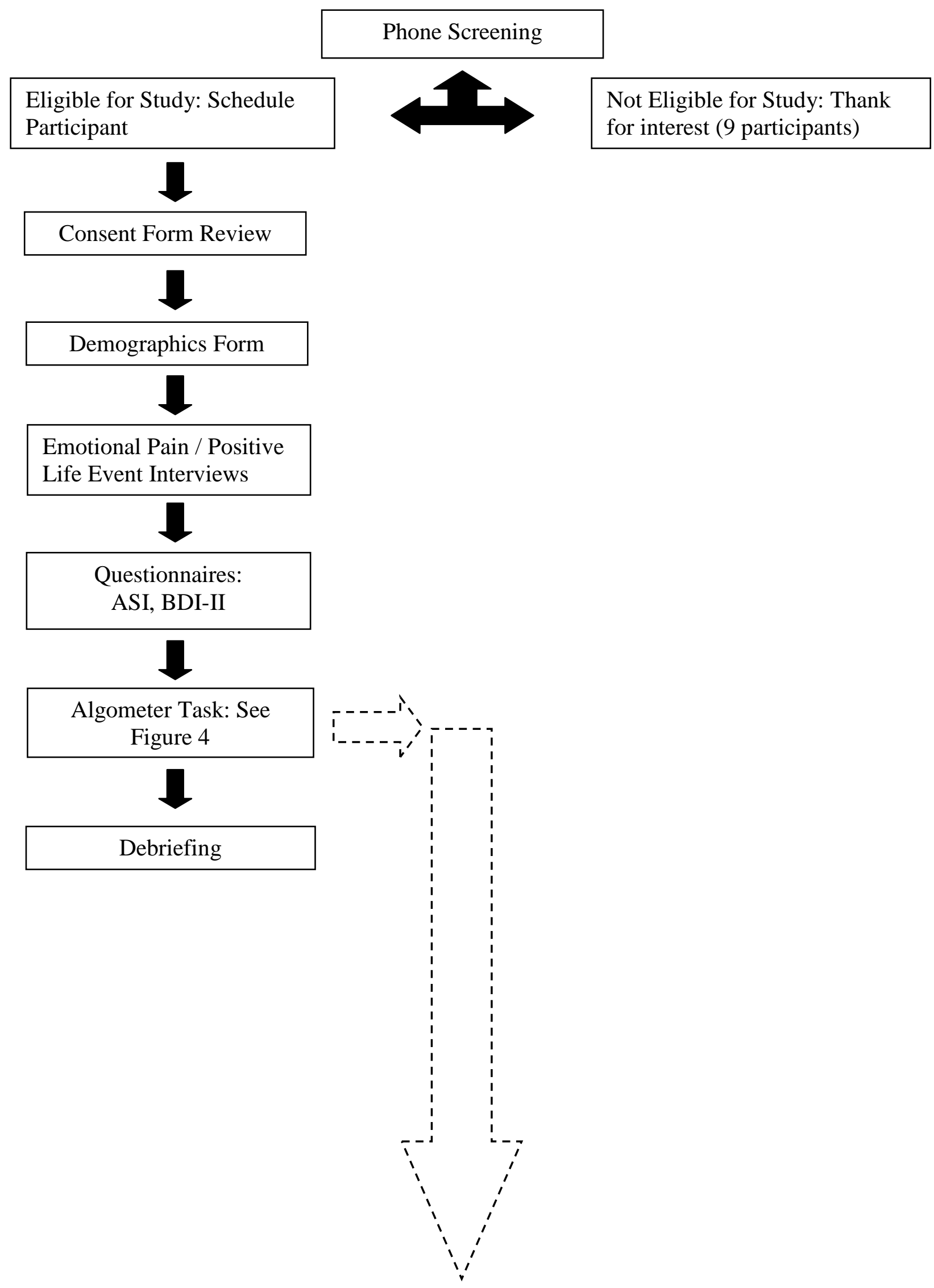


Figure 3

\section{Algometer Procedure}

Set up materials (e.g., threshold \& tolerance signs; algometer) leaving weights hidden in briefcase next to administrator

Introduction of participant and algometer administrator

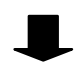

Description of algometer procedure: shown on researchers hand

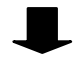

Initial Exposure ( 2-5 min)

1. Place designated finger in the algometer

2. Take out the tan $750 \mathrm{mg}$ weight

3. Read neutral instructions

4. Place platform on the finger

5. Place weight on platform

6. Record pain threshold

7. Record pain tolerance

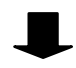

\section{Remove weight from table}

Condition 1( $5-8 \mathrm{~min})$

1. Place designated finger in the algometer

2. Take out the designated weight

3. Read high or low fear instructions (dependent on weight)

4. Place platform on the finger

5. Place weight on platform

6. Record pain threshold

7. Record pain tolerance

\section{Remove weight from table}

(Figure 3 continues on next page) 
(Figure 3 continued)

n

\section{Condition 2 ( 5-8 min)}

1. Place designated finger in the algometer

2. Take out the designated weight

3. Read high or low fear instructions (dependent on weight)

4. Place platform on the finger

5. Place weight on platform

6. Record threshold

7. Record tolerance

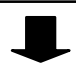

\section{Remove weight from table}

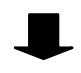

Condition 3 ( 5-8 min)

1. Place designated finger in the algometer

2. Take out the designated weight

3. Read high or low fear instructions (dependent on weight)

4. Place platform on the finger

5. Place weight on platform

6. Record pain threshold

7. Record pain tolerance

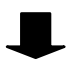

Remove weight from table

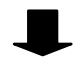

Condition 4 ( 5-8 min)

1. Place designated finger in the algometer

2. Take out the designated weight

3. Read high or low fear instructions (dependent on weight)

4. Place platform on the finger

5. Place weight on platform

6. Record pain threshold

7. Record pain tolerance 
Figure 4

Picture of Algometer Set-Up
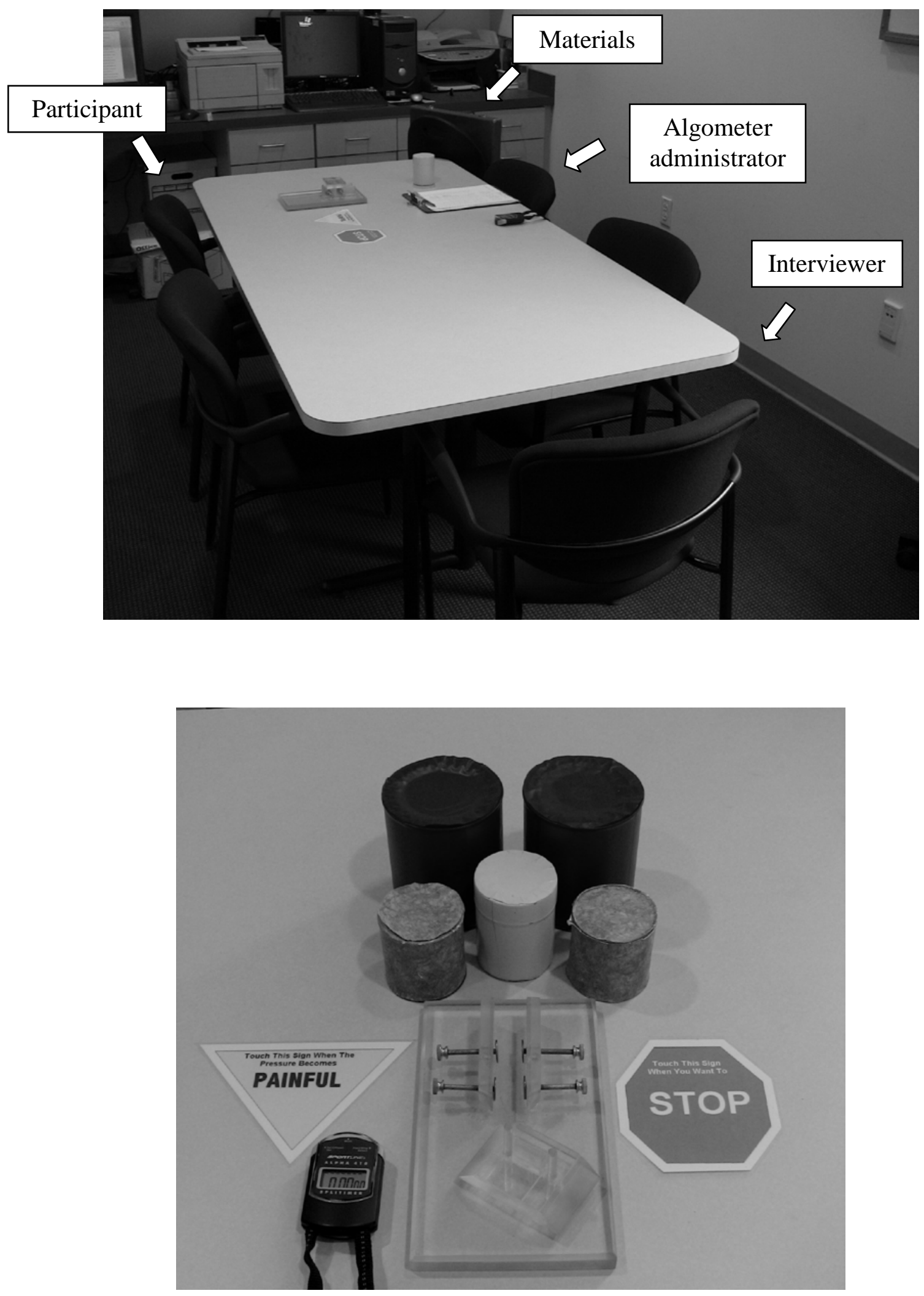
Figure 5

Interaction between Weight and Group for Pain Tolerance

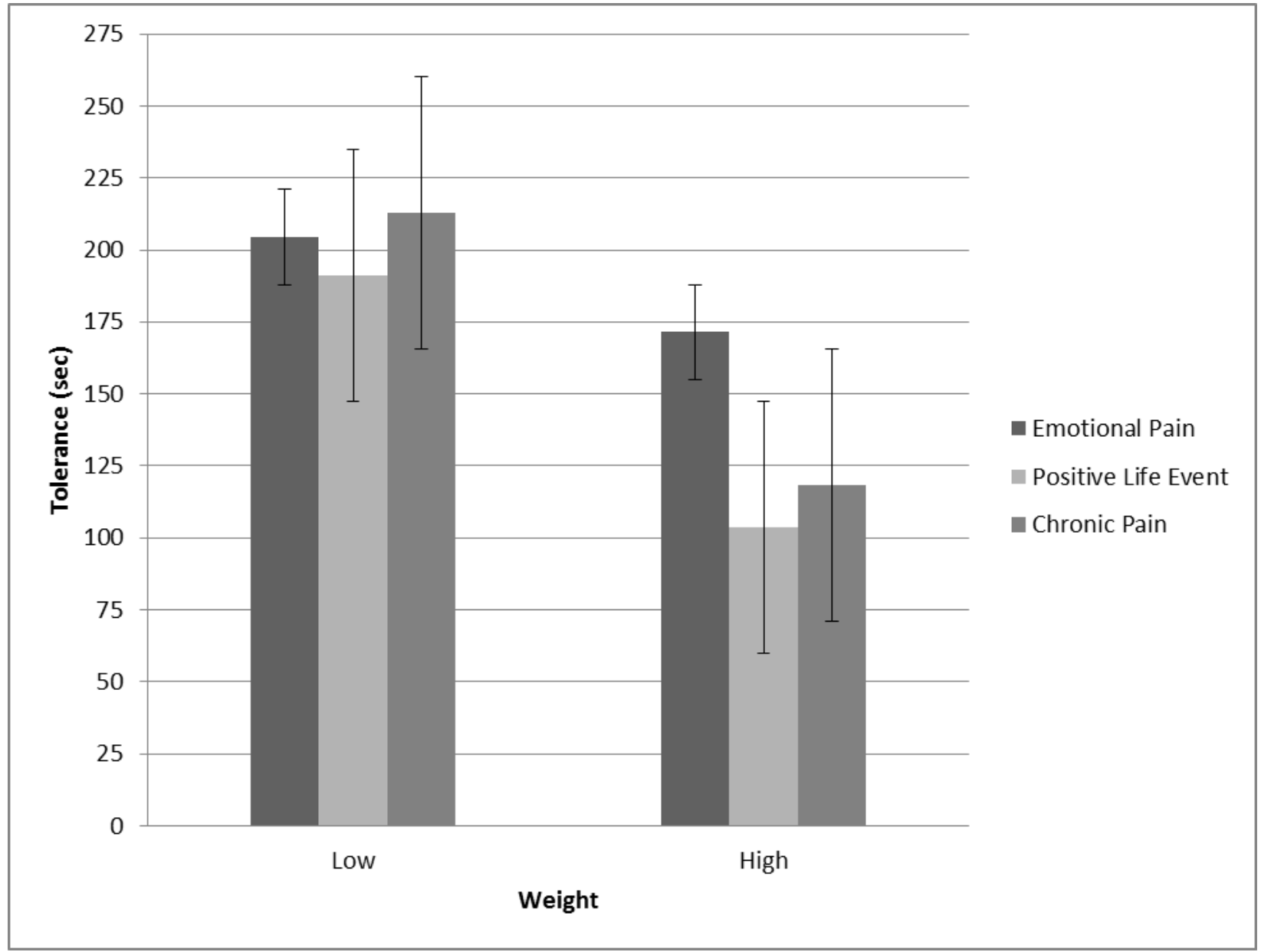

Note. Based on exploratory analyses. 
Figure 6

\section{Consort Flow Diagram}

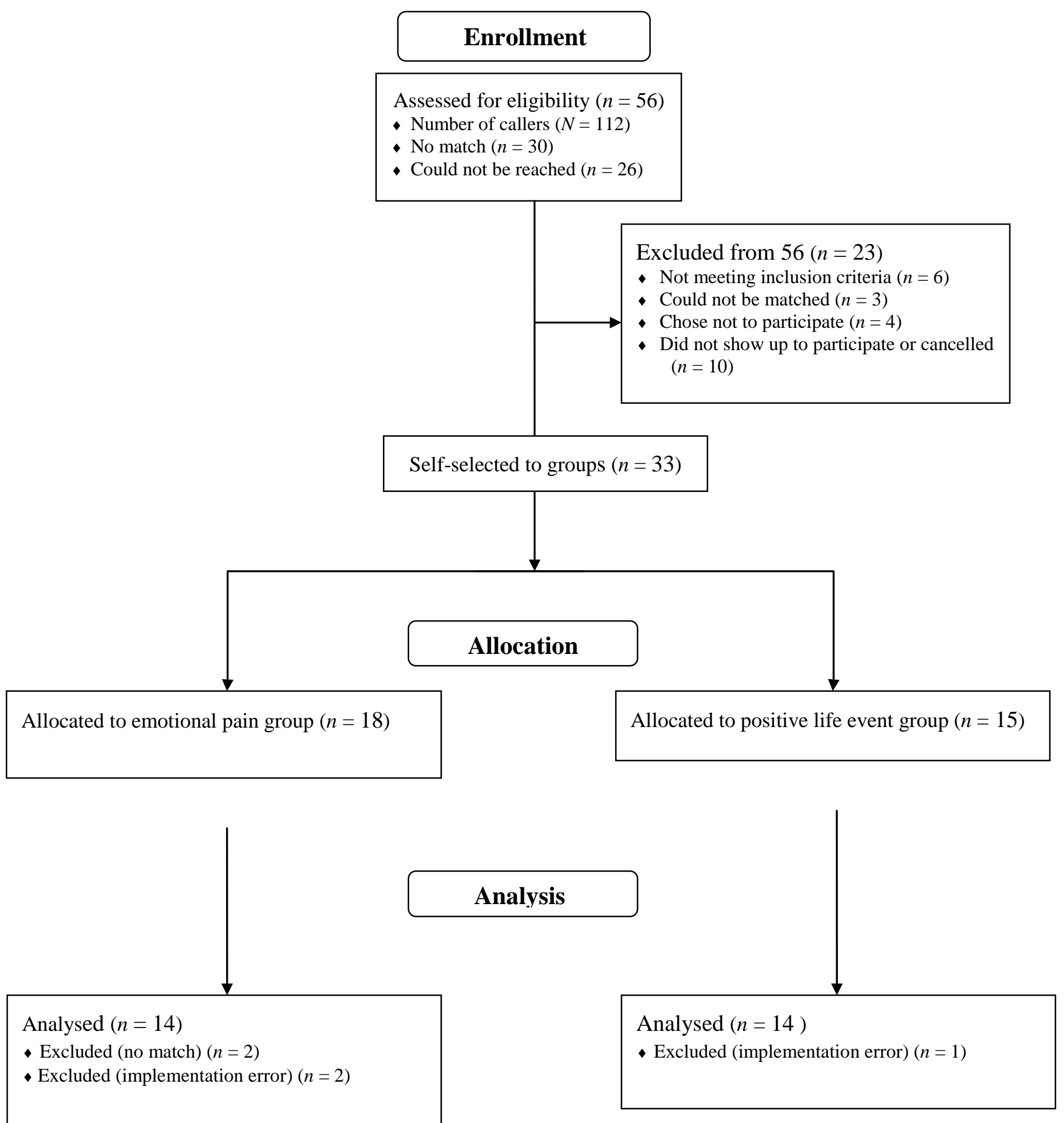

John H. 